\title{
Monetary Policy When Potential OutPut Is UnCERTAin: UNDERSTANDING THE GROWTH GAMBLE OF THE 1990S
}

\author{
YURIY GORODNICHENKO \\ MATTHEW D. SHAPIRO \\ University of Michigan \\ University of Michigan and NBER
}

February 9, 2006

We are grateful to Robert Barsky, Susanto Basu, Alan Blinder, Christopher House, Ed Knotek, N. Gregory Mankiw, David Romer, Glenn Rudebusch, an anonymous referee, the editor and participants in the NBER Monetary Economics program meeting for very helpful comments. We thank Randell Moore for providing us with the Blue Chip forecasts and Refer Gürkaynak, Brian Sack, and Eric Swanson for providing us with their data on forward rates.

(C2005 by Yuriy Gorodnichenko and Matthew D. Shapiro. All rights reserved. Short sections of text, not to exceed two paragraphs, may be quoted without explicit permission provided that full credit, including (C) notice, is given to the source. 


\title{
Monetary Policy When Potential Output Is Uncertain: Understanding the Growth Gamble of the 1990s
}

\begin{abstract}
The Fed kept interest rates low and essentially unchanged during the late 1990s despite a booming economy and record-low unemployment. These interest rates were accommodative by historical standards. Nonetheless, inflation remained low. How did the Fed succeed in sustaining rapid economic growth without fueling inflation and inflationary expectations? In retrospect, it is evident that the productive capacity of the economy increased. Yet as events unfolded, there was uncertainty about the expansion of the capacity of the economy and therefore about the sustainability of the Fed's policy.

This paper provides an explanation for the success of the Fed in accommodating growth with stable inflation in the late 1990s. It shows that if the central bank is committed to reverse policy errors it makes because of unwarranted optimism, inflation can remain in check even if the central bank keeps interest rates low because of this optimism. In particular, a price level target - which is a simple way to model a commitment to offset errors - can serve to anchor inflation even if the public does not share the central bank's optimism about shifts in potential output. The paper shows that price level targeting is superior to inflation targeting in a wide range of situations. The paper also provides econometric evidence that, in contrast to earlier periods, the Fed has recently put substantial weight on the price level in setting interest rates. Moreover, it shows that CPI announcement surprises lead to reversion in the price level. Finally, it provides textual evidence that Alan Greenspan puts relatively more weight on the price level than inflation.
\end{abstract}

Yuriy Gorodnichenko

Department of Economics

University of Michigan

Ann Arbor MI 49109-1220

tel. 734-615-4433

ygorodni@umich.edu
Matthew D. Shapiro

Department of Economics

University of Michigan

Ann Arbor MI 48109-1220

and NBER

tel. 734 764-5419

shapiro@umich.edu

JEL: E52, E58 


\section{Introduction}

The performance of the U.S. economy during the second half of the 1990s was outstanding. Rapid GDP and productivity growth were coupled with a very low unemployment rate and lowand-falling inflation. The sources of this performance are the focus of much of recent research (e.g., Krueger and Solow, 2001). Of course, many factors-including a possible decline in the equilibrium rate of unemployment (Staiger, Stock and Watson, 2001), changes in the structure of the labor force (Blank and Shapiro, 2001), acceleration in technological progress (Jorgenson and Stiroh, 2000, Oliner and Sichel, 2000, Basu, Fernald and Shapiro, 2001), and pure luck (Mankiw, 2002) - likely contributed to the success of the late 1990s.

Nonetheless, few question that the Fed's policies were very important in supporting economic growth with low and stable inflation. Since output was above its historical trend and unemployment was near a historical low, one might have expected the Fed to raise interest rates given its history of past policy actions. Even though inflation was not increasing, a preemptive tightening of monetary policy such as the Fed undertook in 1994 seemed likely. Yet the Fed held interest rates essentially unchanged in the face of output's spurt without an increase in inflation. Indeed, the rate of inflation has trended down since the mid-1990s. Alan Greenspan agrees that monetary policy was expansionary relative to historical standards. He says, “... from 1995 forward, we at the Fed were able to be much more accommodative to the rise in economic growth than our past experiences would have deemed prudent" (Greenspan, 2004, p. 35).

The aim of this paper is to explain why accommodative monetary policy in this period did not increase inflation or inflationary expectations. One possibility is that the expansion of the economy's capacity in the late 1990 s was apparent at the time, so that monetary policy merely accommodated an increase in productive capacity. In retrospect, this explanation has some appeal. 
As the 1990s unfolded, it was, however, much less clear that the economy experienced an increase in capacity. As Greenspan (2004, p. 34) notes, "The rise in structural productivity growth was not obvious in the official data... until later in the decade but precursors had emerged earlier." Though it is now clearly established that a burst of productivity occurred in the late 1990s, there was a sequence of positive surprises as events unfolded. In the context of these very substantial, favorable surprises, the Fed pursued what at the time appeared to be a very expansionary policy.

We argue that the Fed was effectively committed to a price level path. We do not claim that the Fed was following a price level rule per se, but rather that correcting policy mistakes was an important ingredient in its policy actions. We use a commitment to price level stability as a modeling device to represent a general commitment to undo the consequences of policy mistakes rather than allowing the consequences of policy mistakes to have long-term impacts. We show that a policy rule that has an element of the error-correction performs better than a rule without such correction, especially when potential output is not observable. In an economy with forward-looking agents, having the price level as an objective serves to anchor inflationary expectations. Making this commitment can help keep inflation in check even if the central bank is pursuing what looks contemporaneously like a very expansionary policy.

We do not ascribe strict adherence to rules to Alan Greenspan or other central bankers. However, Alan Greenspan and others acknowledge the usefulness of rules as the benchmark for decision making. Greenspan says:

Indeed, rules that relate the setting of the federal funds rate to the deviations of output and inflation from their respective targets ... do seem to capture the broad contours of what we did over the past decade and a half. And the prescriptions of 
formal rules can, in fact, serve as helpful adjuncts to policy, as many of the proponents of these rules have suggested. ... (Greenspan, 2004, p. 38-39).

Although Greenspan indicates that rules are inadequate for dealing with singular events such a stock market crash or the aftermath of the September 11, 2001 terrorist attacks, he says, "A rule does provide a benchmark against which to assess emerging developments" (Greenspan, 2004, p. 39). Our perspective in ascribing a price level target to the Alan Greenspan Fed is very much "as if." This perspective is also found in Taylor's (1993) classic description of interest rate rules. Moreover, the particular policy rules we consider are not the key for our analysis. To reiterate, what is critical is that policy makers have a commitment to reverse the consequences of policy errors.

We consider a continuum of interest policy rules with price level targeting (complete errorcorrection) and inflation targeting (no error-correction) as two extremes. Intermediate cases are equally interesting as they approximate targeting an average inflation rate over several periods. Since these two extremes and intermediate cases are nested, we can easily contrast various regimes in our simple dynamic general equilibrium model and derive a flexible empirical specification that allows us to determine the weights (coefficients) in the policy reaction function.

We provide evidence that the error-correction model fits the late 1990s experience. When the Fed in the late 1990s took the gamble that economic growth had increased, inflation and inflationary expectations remained in check because the public believed that the Fed would quickly counter inflation if the projected rapid growth in productive capacity did not materialize. We show that an inflation targeter, who would not reverse errors, would have had much more difficulty 
keeping inflation under control during the 1990s than a central banker who puts some weight on price stability when setting interest rates.

The organization of this paper is as follows. Section 2 discusses the economic events in the 1990s and how they relate to policy. These facts motivate the analysis by showing how surprising outcomes were in the second half of the 1990s from a historical perspective. Section 3 lays out a standard model that allows us to study policymaking when potential output is not observed. In this section, we show commitment to a stable price level is consistent with the stylized facts about the late 1990s. We also demonstrate that having the price level in the interest rate rule has significant benefits.

In Section 4, we present empirical evidence suggesting that the price level was a part of the Fed's decision rule during the Greenspan era. This econometric evidence suggests that the Fed was indeed pursing the type of policy that our theoretical model shows would perform well against the shocks of the late 1990s. First, we show that a Taylor rule augmented with a price level term fits the data well in the Greenspan era. Second, we show that that the price level reverts after a CPI announcement surprise. Third, we present textual evidence that Alan Greenspan's rhetoric emphasizes the price level as opposed to inflation. Hence, the theoretical and empirical results of the paper present a consistent explanation of the good economic performance during the period when the Fed took its growth gamble. In section 5, we present conclusions.

\section{Monetary Policy in the Late 1990s}

This section provides some evidence that monetary policy in the late 1990s was, by historical standards, unusually accommodative. First, we document Alan Greenspan's views about the new economy. Second, we look at inflation forecasts, based on both backward-looking Phillips 
curves and professional forecasts. Third, we report what a standard Taylor rule would have predicted given the current conditions at the time.

Consider first the evolving views of the Fed Chairman. In December 1996, Alan Greenspan gave his famous "irrational exuberance" speech, that was widely regarded as skepticism concerning the heights that the stock market had reached. ${ }^{1}$ There was, however, a shift in Greenspan's thinking. The FOMC board member Laurence Meyer quotes Greenspan as linking productivity growth to the surprising lack of inflation despite the booming economy at the FOMC meeting on March 27, 1997:

The reason is very clear that productivity is badly underestimated and indeed may be actually accelerating.... We are not at this stage moving into ... an overheated boom ... There is [no] particular urgency to move in a very aggressive way. We are not behind the curve.... But it is crucial to keep inflation low (Meyer, 2004, p. 73).

Greenspan's bet on productivity is truly remarkable given the lack of real time statistical evidence of productivity growth and the lack of support for his view from other FOMC members (Meyer, 2004, Chapter 6).

The assessment of the real economy and its prospects for inflation need not be inferred from speeches, though we will return to textual analysis in Section 4.3. Mechanical projections of inflation based on historical relationships with real variables indicated that inflation might have been expected to increase substantially. Figure 1 shows actual and forecast inflation for the U.S. based on a conventional backward-looking Phillips curve (e.g., Staiger, Stock, and Watson, 1997,

\footnotetext{
${ }^{1}$ The text of the speech refers to balance sheet effects of the stock market and does not confront directly the question of whether there was sufficient economic growth to sustain the stock market values.
} 
2001) where equilibrium unemployment is recalculated using data through 1995 . To construct the forecasts, we use the actual unemployment rate and a beginning-of-the-period estimate of the NAIRU based on Staiger, Stock and Watson's (2001) procedures. The figure shows forecasts over 12-quarter horizons for 1996:4, 1997:4, and 1998:4. Looking ahead from the ends of 1996 and 1997, one would have expected much more inflation based on this historical relationship than was realized. The inflation forecasts in Figure 1 do not embody price level targeting during the Greenspan period because the relationship is estimated over the whole post-war sample and is backward-looking. The inflation forecasts in Figure 1 instead reflect the historical dynamics of inflation, i.e., they show inertial (the short-run dip in forecasted inflation) and increasing inflation over longer horizons from the negative unemployment gap rather than a rational forecast taking into account the credible commitment to targeting the price level that we ascribe to Alan Greenspan.

In a similar vein, professional forecasters overestimated inflation and underestimated GDP growth. In Table 1, we show the forecast errors for GDP growth and inflation for the Blue Chip consensus and the Survey of Professional Forecasters. (Krane (2003) shows the same data for GDP.) Throughout the period, the forecasters consistently underestimated economic growth. The story with inflation is slightly more subtle. Through 1998 , the forecasters systematically overestimated inflation; thereafter, the forecast errors were positive but much smaller. The pattern whereby the professional forecasters underestimate growth yet have inflation expectations that fall substantially fits our story: The forecasters remained unconvinced that the economy could grow faster, yet were confident that the Fed would keep inflation down.

Finally, the Taylor rule predicted significant increases in the federal funds rate, the major policy instrument of the Fed. Using quarterly data for the Greenspan chairmanship, we estimate the conventional Taylor rule for the federal funds rate using current inflation, the unemployment rate 
and two lags of the federal funds rate as regressors. Following Clarida, Gali and Gertler (2000), we estimate the rule by GMM using four lags of the federal funds rate, the inflation rate, the unemployment rate and an index of commodity prices as instruments. To construct projections for the federal funds rate, we estimate the rule up to the date in which we start the forecast and feed the actual inflation rate and unemployment rate and the dynamically forecasted federal funds rates into the estimated rule. Figure 2 shows these 1- to 12-quarter ahead forecasts of the federal funds rate starting at the fourth quarter of 1995, 1996, 1997, and 1998. We find that the actual federal funds rate was well below the rate that would have prevailed if the Fed had continued its previous practice. Ball and Tchaidze (2002) present a similar finding.

Hence, in the second half of the 1990s, the strong performance of output and employment implied that, based on historical patterns, inflation should have increased and monetary policy should have tightened. These forecasts proved to be persistently wrong. In the next section, we present a model and simulations that provide an explanation of these facts.

\section{Model}

\subsection{Setup}

Our theoretical setup is standard in many respects. Its purpose is to provide a framework for studying alternative policies and, in particular, evaluating the policy experience in the second half of the 1990s. To analyze price level and inflation targeting in a unified framework, we suggest a modest but very useful generalization that permits partial price level targeting -i.e., that allows for some revision of the price level target. This novel device is convenient for comparing these alternative policies and is a useful extension to the standard model.

To simplify notation, define the price level gap $\tilde{p}_{t}$ and the inflation gap $\tilde{\pi}_{t}$ as 


$$
\tilde{p}_{t} \equiv p_{t}-p_{t}^{*}
$$

and

$$
\tilde{\pi}_{t} \equiv \pi_{t}-\pi_{t}^{*}
$$

where $p$ is the $(\log )$ price level, $\pi$ is the inflation rate, and stars indicate desired magnitudes. We define inflation targeting (IT) as $\tilde{p}_{t}=\tilde{\pi}_{t}$ and strict price level targeting (strict PLT) as $\tilde{p}_{t}=\tilde{p}_{t-1}+\tilde{\pi}_{t}$. To nest these two regimes, we define partial price level targeting (partial PLT) with the law of motion for the price level target, so

$$
p_{t}^{*}=p_{t-1}^{*}+(1-\delta)\left(p_{t-1}-p_{t-1}^{*}\right)+\pi_{t}^{*} .
$$

The desired price level $p_{t}^{*}$ can have a trend, so our specification of PLT allows for positive average inflation. Equivalently, using the identity $p_{t}=p_{t-1}+\pi_{t}$, under partial PLT the price level gap evolves according to

$$
\tilde{p}_{t}=\delta \tilde{p}_{t-1}+\tilde{\pi}_{t}
$$

where $\delta \in[0,1]$ is the adjustment factor measuring how the desired price level responds to deviations from past targets.

The parameter value $\delta=0$ corresponds to IT. Under IT, past failures to hit the target inflation rate do not affect current decisions - "bygones are bygones" - and the target for the price level is fully revised each period. In contrast, the parameter value $\delta=1$ corresponds to strict PLT. Under strict PLT, there is no revision of the price level target. Note that PLT is typically interpreted as strict price level targeting. For $0<\delta<1$ we have a continuum of cases between IT and strict PLT. By iterating (3) backward, one can find that $\tilde{p}_{t}=\sum_{s=0}^{\infty} \delta^{s} \tilde{\pi}_{t-s}$. Hence, $\delta$ gives the rate that the price level gap adjusts to inflation gaps. 
We embed our nested specification of IT and PLT in a very standard aggregative model.

We assume that the economy evolves according to the system of equations

$$
\begin{aligned}
& p_{t}=p_{t-1}+\pi_{t}, \\
& \tilde{p}_{t}=\delta \tilde{p}_{t-1}+\pi_{t}, \\
& y_{t}=\theta_{1} E_{t} y_{t+1}+\left(1-\theta_{1}\right) y_{t-1}-\sigma^{-1}\left(i_{t}-E_{t} \pi_{t+1}\right)+g_{t}, \\
& \pi_{t}=\theta_{2} \beta E_{t} \pi_{t+1}+\left(1-\theta_{2}\right) \pi_{t-1}+\Lambda\left(y_{t}-y_{t}^{*}\right)+u_{t}, \\
& y_{t}^{*}=y_{t-1}^{*}+\varepsilon_{t},
\end{aligned}
$$

and

$$
i_{t}=\rho_{p} \tilde{p}_{t}+\rho_{\pi} \pi_{t}+\rho_{x}\left(y_{t}-y_{t}^{*}\right)+\rho_{i} i_{t-1},
$$

where $y_{t}$ is output, $y_{t}^{*}$ is potential output, $\pi_{t}$ is inflation, $p_{t}$ is the price level, $\tilde{p}_{t}$ is the price level gap, and $i_{t}$ is the interest rate. The variables $u_{t}, g_{t}$, and $\varepsilon_{t}$ are exogenous, zero mean shocks with variances $\sigma_{T}^{2}, \sigma_{g}^{2}$, and $\sigma_{P}^{2}$, respectively. $E_{t}$ denotes expectations conditional on the information set available at time $t$. We suppress constants. In particular, we normalize $\pi_{t}^{*}$ to 0 , so $\pi_{t}=\tilde{\pi}_{t}$ in (5) and (9).

The interpretation of the model is as follows. Equation (4) is the identity describing the evolution of the price level. Equation (5) is the law of motion for the price level gap. Equation (6) is the log-linearized Euler equation (or the IS schedule; see Clarida, Gali and Gertler, 1999, p. 1691). Equation (7) is the Phillips curve derived from Calvo-type price setting (see Woodford, 2003). The parameters $\theta_{1}$ and $\theta_{2}$ measure the fractions of forward-looking agents in the IS and Phillips curves. $^{2}$ In the standard New Keynesian model, $\theta_{1}=\theta_{2}=1$. By assumption, potential output is a random walk (equation (8)).

\footnotetext{
${ }^{2}$ Ball, Mankiw and Reis (2005), in contrast, have an alternative formulation of the Phillips curve where PLT is the best option. We choose a baseline model that favors IT.
} 
The last equation (9) is the generalized Taylor rule for interest rates. We choose the Taylor rule to close the model because this rule is empirically plausible (Taylor, 1993), it performs relatively well in various setups (e.g., Levin and Williams, 2003, Levin, Wieland and Williams, 1999, 2003), central bankers acknowledge the importance of the rules as a useful policy benchmark (e.g., Greenspan, 2004, Meyer, 2004), and it makes our results comparable to previous findings. Our generalized rule nests IT $\left(\rho_{p}=0, \rho_{\pi}>0, \delta=0\right)$, strict PLT $\left(\rho_{p}>0, \rho_{\pi}=0, \delta=1\right)$ and intermediate cases $\left(\rho_{p}>0, \rho_{\pi}>0,0<\delta<1\right){ }^{3}$ The parameter $\rho_{i}$ captures interest rate smoothing. We assume that the central banker is fully credible and the Taylor rule embodies all his commitments. To reiterate, the central banker does not maximize welfare period-by-period but sticks to his rule.

Our use of the Taylor rule to determine the central bank's policy is an alternative to the approach of specifying an objective function for the central bank and deriving its behavior based on dynamic optimization. Svensson and Woodford (2003) study the question of imperfect symmetric information using the optimization approach. They derive an interest rate rule that includes the price level and excludes inflation (see their equation (75)). Our approach allows us to systematically nest the IT and PLT policies and consider a convex combination of them. Since the structure of the models is so similar, the merits of one approach versus another in this context are mainly expositional. ${ }^{4}$

\footnotetext{
${ }^{3}$ If $\rho_{\pi}=0$ and $\rho_{p}>0$, the Taylor rule becomes, in Woodford's (2003) terminology, quasi-Wicksellian in the sense that the policymaker responds to the output gap and deviations of price level from the target. If, in addition, $\rho_{x}=0$ and $\delta=1$, the Taylor rule is Wicksellian. Note that the generalized Taylor rule that we consider combines proportional (response to the current output gap), derivative (response to current inflation gap) and integral (response to the price level gap) stabilization components. This is an example of PID (proportional-integral-derivative) controllers extensively used in engineering to improve efficiency and stability of feedback controls in dynamic systems (see Lewis's (2003) textbook for examples and discussion). Works by Phillips (1954, 1957) are early applications of PID controllers in economics. ${ }^{4}$ It is worth noting that price level targeting has two subtly different meanings in the optimization versus rules formulations. In the optimization formulation, PLT refers to assigning a positive weight to the price level in the objective function of the central banker. In the rules formulation, PLT refers to having the price level in the policy
} 
The baseline New Keynesian setup we describe above is built on the presumption that agents are rational and all variables are perfectly observable. On the other hand, the literature on measuring potential output and related concepts like the NAIRU (e.g., Staiger, Stock, and Watson, 1997, 2001) documents that measurement or estimation of these economic indicators is notoriously imprecise. Moreover, output itself is subject to numerous revisions (Mankiw and Shapiro, 1986, Orphanides and van Norden, 2002). Because of these considerations, we modify the standard model to make potential output an unobservable quantity. Specifically, we assume that variables $y_{t}^{*}$ and $u_{t}$ are not necessarily observed separately in the Phillips curve. In some specifications, we assume that the public and the central banker observe only $e_{t} \equiv-\Lambda y_{t}^{*}+u_{t}$ and they use filtering techniques to infer the potential output, $y_{t}^{*}$, from the sequence of $e_{t}$. Alternatively, we consider the possibility that the central banker might have a superior estimate of the potential output. We use this possibility to evaluate the experience of the late 1990s when, as discussed in section 2, the Fed appeared to have revised its estimate of potential before professional forecasters.

Since the observed shock $e_{t}$ has random walk $\left(y_{t}^{*}\right)$ and white noise $\left(u_{t}\right)$ components, we use the Kalman/Muth (1960) filter to find the minimum mean squared error forecast of potential output $\hat{y}_{t}^{*}$ as a weighted average of $\left\{e_{t}, e_{t-1}, \ldots\right\}$ so equation (7) becomes

$$
\pi_{t}=\theta_{2} \beta E_{t} \pi_{t+1}+\left(1-\theta_{2}\right) \pi_{t-1}+\Lambda\left(y_{t}-\hat{y}_{t}^{*}\right)+\tilde{u}_{t},
$$

where $\tilde{u}_{t}=e_{t}-\Lambda \hat{y}_{t}^{*}$ and $\hat{y}_{t}^{*}=\lambda \hat{y}_{t-1}^{*}-\frac{1-\lambda}{\Lambda} e_{t}$. The parameter $\lambda$ is of central importance. It shows the fraction of the observed shock attributed to the temporary shock $u_{t}$. Note that rationality is preserved under this learning mechanism in the sense that the true potential output is eventually

reaction function-e.g., the Taylor rule. Svensson and Woodford show that these two formulations can be observationally equivalent in certain circumstances. 
learned and the precision (MSE) of the forecast cannot be improved. Filtering, however, implies that ex post errors in the estimates can be serially correlated.

The rational expectations hypothesis in its strongest form requires that all agents in the economy have identical expectations if they observe identical information sets. On the other hand, heterogeneity in forecasts indicates that the same data can lead to different conclusions because of different models or different subjective priors. To incorporate this heterogeneity in our analysis, we allow the central banker and the public to have different beliefs even when they observe the same data and when their differences in beliefs are common knowledge. When the central banker's belief deviates from that of the public, the public is aware of what the central banker believes. Likewise, the central banker is aware of the public's belief.

Our explanation of the facts about the 1990s discussed above is that the Fed had more optimistic beliefs about potential output than the public. Our account of the later 1990s is inherently episodic. It relies on a divergence in beliefs that would be hard to sustain persistently or repeatedly. Despite the respect of the public for Greenspan's views, our story is that the public did not completely abandon its statistical forecast to align its beliefs with those of the central bank. Consequently, we assume that the public is guided by its own estimate based on the statistically objective Muth filtering, i.e., it forms its own estimate independent from the beliefs of the central banker. Indeed, this is what we mean by the public having different beliefs. The public, however, rationally takes into account consequences of the central banker's actions - that is, the public takes into account that the central banker will make policy based on his different estimate of potential output. $^{5}$

\footnotetext{
${ }^{5}$ Svensson and Woodford's (2003) result that the Kalman filter may be not appropriate if information is asymmetric does not apply to our setting because the central bank follows a Taylor rule rather than optimizes period by period. Furthermore, the filter in our model is applied to an exogenous sequence of shocks.
} 
Our model is similar to those used in other studies that model output uncertainty (e.g., Cukierman and Lippi, 2005, Ehrmann and Smets, 2003, Svensson and Woodford, 2003, Aoki, 2003). The components of these models are essentially identical to ours: a New Keynesian Phillips curve, an IS schedule or other linear constraints, and a signal extraction problem. A key difference in our model is that we augment the Taylor rule with an element of PLT while previous literature focuses on inflation targeting only. In addition, we assume an asymmetry where the central banker has beliefs different from the public.

\subsection{Calibration}

Following Roberts (1995) and Clarida, Gali and Gertler (2000), we set the slope of the Phillips curve to be $\Lambda=0.35$. Like Clarida, Gali and Gertler (1999), we assume that the intertemporal elasticity of substitution (inverse of the slope of the IS schedule) is $\sigma=1$. The quarterly discount factor $\beta$ is set to 0.99 . The fraction of forward-looking agents $(\theta)$ substantially differs across studies. We vary this parameter to observe how sensitive optimal policy is to changes in the share of forward-looking agents. Our baseline calibration is $\theta_{1}=\theta_{2}=1$ so that all agents are forward-looking.

Estimates of the Taylor rule for the Greenspan period typically suggest that the response of the interest rate to the output gap is close to unity and the response to inflation is approximately two. Hence, we assume that $\rho_{x}=1$ and $\rho_{p}+\rho_{\pi}=2$ with $\rho_{p}, \rho_{\pi} \geq 0$ so that determinacy conditions are satisfied.

The interest rate smoothing parameter $\rho_{i}$ is often found to be close to unity. Rudebusch (2002) argues, however, that much of the observed interest rate smoothing is a consequence of serially correlated errors or a persistent omitted variable. We have a complementary explanation for 
observing interest rate persistence. We demonstrate below that PLT produces a large estimate of $\rho_{i}$ even when there is no interest rate smoothing objective. Our baseline calibration has $\rho_{i}=0$.

Next we need to calibrate $\sigma_{T}^{2}$ and $\sigma_{P}^{2}$, the variances of temporary shock $u_{t}$ and permanent shock $\varepsilon_{t}$. To get an idea of $\sigma_{P}^{2}$, we use the variance of the growth rate of potential output as estimated by the Congressional Budget Office (CBO). Note that this estimate probably understates real-time uncertainty associated with unobserved potential output because the CBO's estimate is based on final estimates of GDP. We find that $\sigma_{P}=0.57$ for the 1954-2003 period. To calibrate variances of $u_{t}$ and $g_{t}$, we estimated the Phillips curve (7) and the IS schedule (6) using GMM over the same period. The variance of the residual from the Phillips curve is $\sigma_{T}=0.33$ and the variance of the residual from the IS schedule (6) is $\sigma_{g}=0.54$. We set $\sigma_{P}=1, \sigma_{T}=0.33 / 0.57=0.34$, and $\sigma_{g}=0.54 / 0.57=0.89$ in our baseline specification. The autocorrelation of demand shocks $g_{t}$ is set to 0.9 .

\subsection{Simulation Results: Policy Rules and Growth Gambles}

In this section, we show the results of simulations and relate them to the experience of the late 1990s. Our results suggest that PLT, either strict or partial, could account for the performance of output and inflation when Alan Greenspan shifted to an optimistic outlook for long-run growth. Specifically, we consider three policy rules: inflation targeting $\left(\rho_{\pi}=2, \rho_{p}=0, \delta=0\right)$, partial price level targeting $\left(\rho_{\pi}=1, \rho_{p}=1, \delta=0.9\right)$, and strict price level targeting $\left(\rho_{\pi}=0, \rho_{p}=2, \delta=1\right)$.

These rules allow us to contrast the behavior of the economy when the central bank would, at least, partially offset the impact of adverse shocks to the price level versus policies where the central bank lets "bygones-be-bygones." 
Figure 3 presents impulse responses to a permanent, one percent shock to potential output using our baseline calibration. The central banker correctly believes that potential output has increased. The public does not share this belief. The public does, however, know that the central banker believes potential has increased. Because the public does not share this belief, it uses the statistical forecast. The public does know, however, that the central bank will act on its optimism in setting interest rates. ${ }^{6}$ Price level targeting clearly dominates inflation targeting. After the shock, a central banker pursuing IT would have to increase interest rates and would still experience higher inflation. Specifically, both inflation and interest rate increase by 0.4 percent on impact. In contrast, a central banker pursuing a price level target could keep the interest rate unchanged or even decrease it without igniting inflation. The immediate response of inflation and interest rate is respectively 0.01 and 0.11 percent under partial PLT and -0.07 and 0.06 percent under strict PLT. Moreover, PLT yields more favorable dynamics for output than IT does. The immediate response of output is $0.61,0.78$ and 0.82 percent under IT, partial PLT, and strict PLT. Note that the longrun response of the price level is strikingly different across the regimes. The price level increases by 0.91 percent under IT, by 0.07 percent under partial PLT, and it does not change under strict PLT.

Under PLT, the public knows that any inflation now must be matched with future deflation to bring the current price level back to its starting point. Hence, agents who can reset their prices immediately after the shock would set a lower price than they would under IT. Likewise, agents who are not able to revise their prices on impact do not need to revise them later as significantly as they would under IT. Thus, PLT effectively anchors inflationary and deflationary expectations.

\footnotetext{
${ }^{6}$ Note that a perfectly observable innovation to potential output would result in an instantaneous jump in output to its new potential with no change in all other variables.
} 
Note that the public attributes only a portion of the observed innovation in the Phillips curve equation to a shock to potential output. Given anchored expectations about the future path of inflation, a policymaker can afford expansionary policy by cutting real interest rate. Via the IS schedule, this change in real interest rates raises output. Therefore, output converges faster to its new steady state after a permanent shock to potential output. If the shock turns out to be transitory, then the central banker does not need to significantly raise interest rates to correct the policy instrument in the next period because inflation is kept in check by the PLT.

The findings for the baseline specification survive a number of modifications. Adding backward-looking agents $\left(\theta_{1}=\theta_{2}=0.5\right)$, which makes output and inflation more persistent, does not qualitatively change the ranking of the regimes (Figure 4). After one percent increase in potential output, the immediate response of inflation under IT is 0.11 percent, while the response is 0.02 percent under partial PLT and zero under strict PLT. Note that the inflation response function is now hump-shaped. In addition, the PLT regimes predict that the central banker should reduce interest rates. The response of output is similar across regimes. As the share of backward-looking agents increases, the advantage of PLT diminishes and the responses (under PLT) become oscillatory. Likewise, interest rate smoothing $\left(\rho_{i}=0.9\right)$ decreases the gap between PLT and IT (Figure 5), but the ranking of the regimes is preserved. Hence, forward-looking behavior combined with the central bank being more optimistic than the public is the key ingredient in our account of the late 1990s. ${ }^{7}$

\footnotetext{
${ }^{7}$ We do not report the cases when the public is more optimistic about potential output than the central bank. In that case, there is substantial downward pressure on inflation because the public expects future monetary ease as the central banker learns about the improvement in productive capacity. Under IT, the decline in inflation is so large that the interest rate falls sharply despite the central banker's skepticism about a shift in potential output. In contrast, under PLT, the decline in interest rates is attenuated because the public sets current prices higher in anticipation of future accommodative policy. So the same error-correction logic applies as in our baseline case where the central banker is more optimistic. The model where the public is more optimistic, however, does not fit the facts of the late 1990s. We
} 
As stressed above, our model uses a Taylor rule rather than period-by-period optimization to determine monetary policy. It is nonetheless interesting to ask how the policy rules perform as measured by a loss function. In the appendix, we present such welfare calculations. In summary, we find that PLT can not only match the stylized facts of the late 1990s, but also that undoing past policy mistakes as under PLT is generally a better policy regime than letting bygones be bygones as under IT. Intuitively, by introducing history dependence in the policy rule, PLT anchors inflationary expectations and can reduce the volatility of both inflation and output. Irrespective of whether information is symmetric or asymmetric, PLT generally dominates IT in terms of social welfare as long as sufficiently many agents are forward-looking. The forward-looking behavior is critical because PLT affects the economy by controlling expectations for future interest rates and prices. If agents are backward-looking, promising changes in the future path of the policy instrument does not anchor inflationary expectations and, consequently, there is no value to commit to PLT. (See appendix for further details). Importantly, PLT keeps inflation in check even when it turns out that the policymaker was overly optimistic or overly pessimistic about potential output. ${ }^{8}$ Hence, we show that PLT can be the best policy not only in certain environments (e.g., Svensson, 1999), but also in uncertain environments.

PLT may be criticized on the grounds that central banks may fail to make the very tough decision required to pull down the price level following adverse shocks and, possibly, to generate a deflation (e.g., Tobin, 1984, Friedman and Kuttner, 1996, Friedman, 1999). This critique does not apply to the situation we have analyzed. PLT keeps inflation in check even when it turns out that the policymaker was overly optimistic about potential output. Hence, policy errors do not have

also consider an alternative specification where the growth rate, rather than the level, is subject to shocks. These results (not reported) have the same qualitative features as those highlighted in this paper.

${ }^{8}$ PLT dominates IT even if the central banker is consistently more optimistic or pessimistic than warranted by the Muth/Kalman filtering, i.e., the central banker's $\lambda$ can be systematically different from $\lambda$ in the statistically objective Muth/Kalman filter. 
serious consequences that require very contractionary policy. Recall that since PLT anchors inflation there is little variation in inflation in the first place. Consequently, it should be feasible for the central bank to maintain the credibility that our analysis presumes. ${ }^{9}$ Furthermore, as long as the desired price level has a trend (i.e., the desired inflation rate is positive), there is room for the price level to revert to its target through a period of lower-than-average inflation without having prices actually fall. Hence, a central banker can simultaneously pursue PLT and the goal of avoiding deflation.

\section{Testing for Price Level Targeting}

The impulse responses under PLT for the baseline calibration appear to be consistent with the experience of the late 1990s: relatively stable interest rates, soaring output, and low inflation. In contrast, IT would have led to somewhat higher inflation, somewhat higher interest rates and somewhat lower output in response to the same shocks. The foregoing analysis provides circumstantial evidence that PLT or an approximation to it contributed to the low inflation and high growth seen in the late 1990s. In this section we present direct evidence that suggests that the Fed was indeed behaving consistently with having the price level in its objective in recent years. First, we test if the fed funds rate responded to the price level along the lines of the model in the previous section. Second, we test if the price level reverts after inflation surprises. Third, we perform content analysis of central bankers' rhetoric to test if our account of the late 1990s has textual support. ${ }^{10}$

\footnotetext{
${ }^{9}$ In addition, the generalized Taylor rule with an element of PLT mimics Woodford's optimal policy rule from a timeless perspective, so commitment problems are likely to be attenuated.

${ }^{10}$ Additionally, one can test unit root implications of the PLT. Note that if the central banker sticks to PLT, discrepancies between the actual price level and the desired (target) price level are transitory. Hence the (log) actual price level is trend stationary, where the trend is some target price level. In contrast, IT implies that the price level has a unit root. So, whether or not the price level has a unit root helps distinguish between the two policies. Unfortunately, this test of PLT is hardly decisive in our case because the test has low power in small samples and it is sensitive to inclusion of trend breaks.
} 


\subsection{Taylor rule}

Starting with Taylor (1993), many studies document that the Taylor rule in various formulations describes U.S. monetary policy fairly well. It is very tempting to take this as evidence for IT. We show that such a conclusion would be premature. Our parameter estimates suggest that there is a substantial weight on the price level in the Taylor rule in the Greenspan period, but not earlier. Of course, Alan Greenspan has never been an advocate of monetary rules. He acknowledges, however, that a rule may serve as a useful benchmark for policy actions (e.g., Greenspan, 2004). Our estimates of a Taylor rule may capture key elements of a much more complex reaction function.

Suppose the central banker uses the generalized Taylor rule with a price level target as well as inflation target,

$$
i_{t}=\rho_{p} \tilde{p}_{t-1}+\rho_{\pi} \pi_{t}+\rho_{x} x_{t}+\rho_{i} i_{t-1}+v_{t},
$$

where $x_{t}=y_{t}-y_{t}^{*}$ is the output gap and $v_{t}$ is an exogenous innovation to monetary policy. Using (5), we quasi-difference (11) to eliminate the unobserved $\rho_{p} \tilde{p}_{t-1}$ term,

$$
i_{t}=\rho_{\pi} \pi_{t}+\left(\rho_{\pi}-\rho_{p} \delta\right) \pi_{t-1}+\rho_{x} x_{t}-\rho_{x} \delta x_{t-1}+\left(\rho_{i}+\delta\right) i_{t-1}-\delta \rho_{i} i_{t-2}+v_{t}-\delta v_{t-1} .
$$

In contrast, a typical specification in the context of IT (e.g., Clarida, Gali and Gertler, 2000) is

$$
i_{t}=a_{1} \pi_{t}+a_{2} x_{t}+\rho_{1} i_{t-1}+\rho_{2} i_{t-2}+v_{t} .
$$

Specifications (12) and (13) are quite similar. The PLT provides clear falsifiable implications about signs and restrictions on the coefficients. In particular, PLT specification (12) predicts:

1. A negative coefficient on the lagged output gap

2. A large, positive (possibly close to unity) coefficient on the lagged interest rate and a small, negative coefficient on the second lag of the interest rate

3. An overidentifying restriction on the parameters (six coefficients and five parameters) 
Note that absent the price-level term in (9), the lagged terms in (12) involving $\delta$ would be irrelevant. That is, without a price level objective, $\delta$ is not identified.

Note that equation (12) also has an MA term whose coefficient is equal to the adjustment factor $\delta$. For a variety of reasons - such as time aggregation, measurement errors, serial correlation from learning - a structural interpretation of a moving average root is problematic. We did nonetheless examine the MA coefficient and found that it is generally not statistically significantly different from zero, and it is extremely sensitive to minor specification changes. Hence, we do not impose it and instead we use specification ${ }^{11}$

$$
i_{t}=\rho_{\pi} \pi_{t}+\left(\rho_{\pi}-\rho_{p} \delta\right) \pi_{t-1}+\rho_{x} x_{t}-\rho_{x} \delta x_{t-1}+\left(\rho_{i}+\delta\right) i_{t-1}-\delta \rho_{i} i_{t-2}+e_{t}
$$

and its unrestricted analogue

$$
i_{t}=a_{1} \pi_{t}+a_{2} \pi_{t-1}+a_{3} x_{t}+a_{4} x_{t-1}+\rho_{1} i_{t-1}+\rho_{2} i_{t-2}+e_{t} .
$$

We estimate (14) and (15) for two subsamples: 1955-1979 (pre-Greenspan) and 1982-2003 (late Volker and Greenspan era). ${ }^{12}$ The output gap $x$ is measured as a residual after HP-filtering log real GDP. The price level is measured with the GDP deflator and, consequently, inflation $\pi$ is the growth rate of the GDP deflator. The federal funds rate is our $i$. Following Clarida, Gali and Gertler (2000), we use GMM to estimate the interest rate rules. The set of instruments includes four lags of the output gap, inflation, log commodity price index, and the federal funds rate. Data are quarterly.

Table 2 presents the estimates of the restricted specification (14). The $p$-values for the test of the restrictions are 0.27 and 0.12 for the two periods. The parameter $\delta$ controls the rate at which past errors affect the price level target. For the pre-Greenspan sample, the point estimate is 0.364 .

\footnotetext{
${ }^{11}$ Aoki (2003) derives a similar rule in a setup where the data are revised. Hence, PLT can be observationally equivalent to other models, e.g., models with a noisy signal (Aoki, 2003). There could be other models yielding the same reduced-form. Although the interpretation of coefficients could be different, the ultimate outcome is the same. ${ }^{12}$ We exclude 1979-1981 because the Fed used a different operating target (e.g., Bernanke and Mihov, 1998).
} 
For the Greenspan sample, it is 0.814 . Hence, neither period has strict PLT, but the Greenspan era is characterized by much less discounting of past errors, i.e., it is much closer to strict PLT than the earlier period. The differences are statistically and economically significant. IT targeting causes the new price level trend to shift by the entire amount of the inflation error. With a $\delta$ of 0.364 , after four quarters the new trend is within 2 percent $\left(0.364^{4}=.02\right)$ of the IT level; with a $\delta$ of 0.814 , the new trend is only within 43 percent $\left(0.814^{4}=0.43\right)$ of it. On the other hand, the estimated $\delta$ of 0.814 is much less hawkish than strict PLT. Finally, note that a $\delta$ of 0.8 is close to the optimal level that we find in our welfare calculations (see appendix).

Note that the interest rate smoothing motive is much stronger in the pre-Greenspan period than in the Greenspan period, as the estimate of $\rho_{i}$ falls from 0.74 to 0.17 . In addition, $\left(\rho_{i}+\delta\right)=$ $0.17+0.81=0.98$ is a value that is often found in reduced-from specifications. As we show above, interest rate smoothing and PLT have very similar implications for the Taylor rule. Hence, our approach provides an alternative explanation for why the lagged interest rate is so important in explaining the variance of the federal funds rate and why the coefficient is so close to unity.

This point can be made clear by considering the unrestricted estimates in Table 3. Columns (2) and (3) give the unrestricted estimates for the two sample periods. Columns (5) and (6) give the reduced-form estimates implied by the restricted estimates in Table 2. Finally, for comparison, we include the specification of Clarida, Gali and Gertler (2000) that includes no lags of inflation and the output gap. ${ }^{13}$ Table 3 shows that the presence of lagged interest rates in the Taylor rule can arise from PLT even if there is no interest rate smoothing objective.

The short-run response of the federal funds rate to the output gap is significantly larger for the Greenspan period than for the pre-Greenspan period. The long-run response of federal funds

\footnotetext{
${ }^{13}$ The results with respect to the output gap are slightly different because we use the HP filter while Clarida, Gali and Gertler (2000) use a quadratic trend.
} 
rate to the output gap $\left(\frac{\rho_{x}}{1-\rho_{i}}\right)$ is roughly unchanged: 0.95 for the Greenspan period and 1.11 for the pre-Greenspan period. Importantly, the estimate of the coefficient on the lagged output gap in the unrestricted model (15) has a negative sign, which is consistent with PLT. Moreover, the coefficients for the current and lagged output gap are of comparable absolute magnitudes as predicted by PLT.

Finally and most importantly, we observe a tremendous change in $\rho_{p}$ and $\rho_{\pi}$ reflecting the relative importance of PLT and IT, respectively. The marginal short-run effect of inflation on the interest rate, $\rho_{\pi}$, is economically identical for both subsamples. In contrast, point estimates of response to the price level gap, $\rho_{p}$, increases ninefold from 0.04 to 0.37 . In sum, the long-run response of the federal funds rate to inflation, $\frac{1}{1-\rho_{i}}\left(\frac{\delta}{1-\delta} \rho_{p}+\rho_{\pi}\right)$, increases from 0.66 in the 19551979 sample to 2.66 in the $1982-2003$ sample. These estimates, together with the change in the estimate of $\delta$ from 0.364 to 0.814 (see Table 2), suggest that a combination of toughness about inflation and taking into account passed inflation errors—i.e., partial PLT—characterize monetary policy under Greenspan. The simulations that we presented in Section 3 provide circumstantial support for our argument. The evidence of this section provides some direct support for our contention that a nominal anchor had an important role in monetary policy under Greenspan.

We confirm the results of Clarida, Gali and Gertler (2000): the Fed responded to inflation in 1982-2003 much more aggressively than in 1955-1979. However, we give a different interpretation of why we observe a more aggressive response. Clarida, Gali and Gertler put all weight on a short-run response propagated by interest rate smoothing while our estimates show that price level targeting can mediate the cumulative response of interest rate policy to inflation. ${ }^{14}$

\footnotetext{
${ }^{14}$ We run a number of robustness checks. The qualitative conclusions are insensitive to changes in the definition of price index (e.g., CPI or PPI instead of GDP deflator), slack capacity (e.g., unemployment rate instead of the output gap,
} 


\subsection{Response to inflation surprises}

In this section we consider how the price level responds to inflation surprises. ${ }^{15}$ If a policy regime has error-correction, an increase (decrease) in the price level due to surprisingly high (low) inflation is offset in the future and the price level reverts back to the projected path. In contrast, there is no price level reversion under a policy regime where bygones are bygones. Thus, the impulse response of the price level to inflation surprises can help us to differentiate policy regimes. ${ }^{16}$

We implement this test as follows. We measure expected inflation as the median forecast in the Money Market Services issue published on the Friday before the release of the Consumer Price Index (CPI). The inflation announcement surprise is computed as actual inflation minus expected inflation. The compiled monthly series covers 1980 to the present. There are some dynamics to inflation surprises, so we estimate a standard VAR with two variables: log consumer price index and inflation surprises. The estimation period is 1982 to 2003. Lag length selection criteria suggest that the optimal number of lags is four.

Using the estimated VAR, we construct the impulse response of the CPI to 0.1 percent inflation surprise (Figure 6). We find that the price level falls by 0.08 after approximately one year and remains there in the long-run. The point estimate of the long-run response is remarkably consistent with partial PLT when reversion to the targeted price level path is not complete, that is, it corresponds to a $\delta$ of 0.8 . Note that 95 percent confidence bounds do not include zero. Thus, we can reject bygones-be-bygones policy regime. The qualitative conclusion of price level reversion in

deviation of output from the CBO's estimate of the potential output) and the time span of the Greenspan period (e.g., 1984-present, 1987-present). We also estimate (14) using continuously-updated GMM that is robust to the weak instrument problem (Stock, Wright and Yogo, 2002) and we find the same qualitative results. All these perturbations to the baseline specification lead to the same conclusion: the importance of PLT significantly increased during the Greenspan chairmanship.

${ }^{15}$ We are grateful to N. Gregory Mankiw for suggesting this test.

${ }^{16}$ In contrast to unit root tests, this test differentiates expected and unexpected changes in inflation and the price level. Thus low frequency variation in the targeted inflation and price level does not contaminate the inference, and the test should have more power than unit root tests. 
response to inflation surprises does not change when we experiment with a larger number of lags or alternative samples. ${ }^{17}$ Unfortunately, we do not have data on CPI surprises for the 1970s or earlier, so we cannot test for regime shifts as we do in the previous section.

In summary, the response of the price level to inflation surprises is consistent with correcting for inflation surprises rather than with letting bygones be bygones. The point estimates of the long-run response are also in line with our evidence from the estimated Taylor rule, that is, $\delta$ is about 0.8 . Therefore, two starkly different sources of evidence — the generalized Taylor rule and the mean reversion of the price level after a surprise-yield nearly identical estimates of the adjustment of the price level to policy errors. ${ }^{18}$ The estimate is quite close to price level targeting/complete error offset. It is far from inflation targeting/bygones-be-bygones.

\subsection{Textual Analysis: Inflation versus Price Level}

In this section, we provide some textual support for our account of the late 1990s. Ideally, we would like to have a direct statement of a central banker that he or she targets a particular variable. This evidence is hard to come by because U.S. central bankers typically are purposefully vague. Moreover, as we suggest above, PLT or IT are only modeling shortcuts for much more general policies. Nevertheless, they should capture the essence of bygones-be-bygones versus error-correction.

\footnotetext{
${ }^{17}$ Gürkaynak, Sack and Swanson (2003, 2005; henceforth, GSS) look at the impact of many surprises on the forward rates and forward inflation compensation, which is defined as the difference in returns on nominal and inflation-indexed Treasury bonds. Owing to data limitations, they focus on cumulative, multiyear inflation compensation. In the spirit of their work, we run a bivariate regression where the 9-year cumulative inflation compensation is the dependent variable and the CPI inflation surprise is the only explanatory variable. We find that the response of inflation compensation to inflation surprises is statistically and economically small. GSS find a larger but still statistically insignificant response. Our results differ for two reasons. First, we look at the response to CPI inflation surprises only, while they examine it jointly with 11 other surprises. Second, we look at the innovations of CPI inflation surprises because the "surprises" are serially correlated. These differences in specifications explain why we get different point estimates. In any case, there is no significant effect at long horizons. Given our findings in Figure 6 that the mean reversion occurs within the year, the long-horizon tests are not particularly informative.

${ }^{18}$ Transitory measurement error in the CPI would also lead to the type of mean-reversion we document here. Hence, the strength of this evidence derives mainly from its consistency with our estimates of the Taylor rule.
} 
We employ the simplest content analysis to test if our theory has textual support in central bankers' speeches, papers, books, etc. Specifically, we compare the relative frequency of words associated with different policy regimes across central bankers. Put differently, the central banker can deliberately refrain from using direct statements to describe policy, but can indicate the regime (maybe, unconsciously) through his or her choice of words. The underlying assumption of the content analysis is that frequently appearing words reflect the objectives or concerns of the authors. This approach has been used extensively in political science, sociology and psychology. (See Neuendorf, 2002; see also Shiller (1997) for an application in economics.)

To make the analysis operational, we need to identify words that point to policy objectives. We associate concerns for the price level with the words price(s), price level, price stability, stable prices, price index. We associate concerns for inflation with the words inflation, stable inflation, low inflation, and zero inflation. To control for possibility that some central bankers use keywords more frequently than others, we calculate the relative propensity to mention inflation as the frequency of "inflation" words minus the frequency of "price level" words.

We compare Alan Greenspan with Alan Blinder and Ben Bernanke. ${ }^{19}$ The list of analyzed materials is given in appendix Table A1. The criterion for selecting a text is relevancy, i.e., a speech, article or book should be about or related to monetary policy. We present simple summary statistics in Table 4, panel A. The first block of the panel shows the frequency of inflation words. Bernanke mentions inflation twice as often as Blinder and three times as often as Greenspan. On the other hand, Bernanke and Greenspan mention price level words (the second block) equally often and more frequently than Blinder. When we compute the relative propensity to mention inflation

\footnotetext{
${ }^{19}$ It would be interesting, though tedious because of the lack of electronic texts, to compare Alan Greenspan with other chairmen such as Arthur Burns and William McChesney Martin.
} 
(the third block), Bernanke is the leader (0.623) while Greenspan has the smallest propensity $(-0.344)$ and Blinder is in between (0.241).

To test the difference in the relative propensity to mention inflation, we use difference-indifferences estimator, i.e., we regress the relative propensity to mention inflation on two dummy variables for Blinder and Bernanke (Greenspan is the omitted category). The coefficients give us the excess rate of mentioning inflation relative to the price level.

Panel B of Table 4 presents estimation results. Both coefficients are positive and statistically significant at the 1 percent level. ${ }^{20}$ Hence, the estimates suggest that relative to other central bankers Greenspan uses words that are associated more frequently with maintaining a stable price level than with having low, stable inflation. This confirms our casual perception that Alan Greenspan rhetoric focuses much more on the price level than Alan Blinder's or Ben Bernanke's. In contrast, the disproportionate mentioning of inflation suggests that Blinder and Bernanke could be more inclined to advocate bygones-be-bygones. For Bernanke, who has promoted inflation targeting rules, this finding is not a surprise, so it validates our content analysis. In contrast, Alan Blinder's propensity to mention inflation relative to the price level is indirect evidence that he focuses more on inflation. The comparison of Alan Greenspan with these other prominent economists and central bankers shows that Alan Greenspan's attention to the price level in his rhetoric is distinctive.

\section{Conclusions}

In the late 1990s, Alan Greenspan and the Federal Open Market Committee took a gamble. They kept interest rates essentially steady in the face of extraordinarily strong output growth and record-low unemployment rates. If the Fed had followed its historical reaction to economic

\footnotetext{
${ }^{20}$ The results change only marginally when we remove Greenspan's speeches on Nov 7, 1997 and Jan 3, 1998 when he discussed measurement of prices.
} 
conditions, it would have raised interest rates. Instead the Fed kept interest rates low because it believed that the productive capacity of the economy had expanded. Though it is now clear that there was such a shift, at the time the evidence for it was quite limited. Why did the gamble pay off? Even though the Fed turned out to be correct about potential output growth, why did inflation not increase as private agents took into account the risk that the Fed was being too stimulative when they set their price and inflation expectations?

This paper provides an explanation for the success of the Fed in accommodating noninflationary growth in the late 1990s. A commitment of the Fed to reverse policy errors had it been too optimistic about the capacity of the economy can explain why inflation remained in check despite historically loose monetary policy. In particular, the paper shows that a price level target, either strict or partial, can serve to anchor inflation even if the public believes the Fed is overly optimistic about potential growth. The expectation that policy errors will be reversed leads to very favorable outcomes. The Fed is able to gamble on its belief that capacity has increased without the public raising inflationary expectations because the public knows that the Fed will reverse itself in the event the gamble does not pay off. The costs of reversing itself in this case are also low because the price level target keeps inflation low even in bad realizations. So only a modest disinflation is needed to reverse policy errors.

The paper shows that price level targeting is superior to inflation targeting in a wide range of situations. The analysis does not depend on strict price level targeting. In particular, our formulation nests inflation targeting and strict price level targeting within a specification that allows for partial adjustment of the price level target to past inflation. For price level targeting to have these favorable properties, sufficiently many agents must be forward-looking. If not, then there is no value to the commitment to reverse errors. 
The paper also provides econometric evidence that the Fed, in contrast to earlier periods, has recently put substantial weight on the price level in setting interest rates. A generalized Taylor rule puts weight on the price level gap as well as the inflation gap in the Greenspan era. In the preGreenspan period, there is no evidence of price level targeting. Moreover, the presence of the price level gap in the Taylor rule provides an explanation that does not rely on interest-rate smoothing or serially correlated policy errors for the significance of lagged interest rates in standard Taylor rules. Price level targeting induces error-correction that resembles serial correlation of interest rate decisions in specifications that do not control for the price level gap. We also find that the price level reverts significantly in response to CPI announcement surprises. This finding provides complementary evidence that the Fed has a policy to offset surprises rather than a policy of letting bygones be bygones. The degree of the price-level reversion matches almost exactly what we estimate based on the generalized Taylor rule. Finally, we perform a content analysis of the language of Alan Greenspan, Alan Blinder and Ben Bernanke. This analysis supports the claim that Alan Greenspan puts a relatively greater weight on the price level when compared to either Ben Bernanke, who advocates explicit inflation targeting, or Alan Blinder, who does not advocate explicit rules.

Our analysis does not ascribe strict adherence to a price level target, or indeed any other rule, to Alan Greenspan or the Fed. Rather, it shows that there is both theoretical and empirical support for the contention that commitment to correcting past errors was a part of Federal Reserve decision making in recent years and that this commitment contributed to the superior performance of the U.S. monetary policy in the late 1990s.

Our nesting of inflation targeting and price level targeting shows that these two policies lie on a continuum. If an inflation-targeting central banker has a preference for being on average in the 
middle of an inflation target range, then inflation targeting will partially anchor the price level relative to a deterministic trend. Our model of partial price level targeting is a way to build in this tendency to offset past shocks in some inflation targeting regimes. Consequently, our analysis admits the possibility of a high degree of continuity between the policy followed under Alan Greenspan's and Ben Bernanke's leadership. 


\section{Appendix: Welfare analysis}

To compare policy rules, we consider the following loss function:

$$
\mathcal{L} \equiv \sum_{t=0}^{\infty} \beta^{t}\left(\omega_{x}\left(y_{t}-y_{t}^{*}\right)^{2}+\pi_{t}^{2}\right) \equiv \omega_{x} \mathcal{L}_{x}+\mathcal{L}_{\pi}
$$

To be clear, we use this function only to evaluate policies, not to derive them. Woodford (2003) shows that this loss function approximates welfare loss when the Phillips curve is as in (7) with $\theta_{2}=1$. We put a zero weight on the price level gap so as to give no direct benefit to PLT. ${ }^{21}$

Woodford (2003) estimates $\omega_{x}=0.05$. In a slightly different setting, Erceg and Levin (2002) obtain a much larger $\omega_{x}=1$. Because price level targeting generally reduces the volatility of inflation and increases the volatility of output, we set $\omega_{x}=1$ to bias the findings against PLT.

After specifying the loss function, we randomly draw shocks in the IS and Phillips curves, compute dynamics of the variables for each targeting regime, calculate the social loss, and average the results over 500 replications. The resulting isoloss map for our baseline calibration is presented in Panel A, appendix Figure A1. The vertical axis of the figure plots the parameter $\rho_{p}$ in the generalized Taylor rule $i_{t}=\rho_{p} \tilde{p}_{t}+\rho_{\pi} \pi_{t}+\rho_{x}\left(y_{t}-y_{t}^{*}\right)+\rho_{i} i_{t-1}$ with $\rho_{\pi}=2-\rho_{p}$. The horizontal axis plots the PLT adjustment factor $\delta$. The point $\rho_{p}=0$ and $\delta=0$ corresponds to IT (no weight on the price level gap). The right edge of the figure with $\delta=1$ corresponds to regimes with strict PLT. The point $\delta=1$ and $\rho_{p}=2$ is strict PLT with no weight on the inflation gap. The points with $\delta$ between zero and one correspond to partial PLT.

Relative to IT, PLT (partial or strict) always reduces the volatility of inflation. Under the baseline calibration, PLT can cut the social loss by 66 percent and the volatility of inflation by more

\footnotetext{
${ }^{21}$ Note that the loss function does not penalize for volatile interest rates. See Levin and Williams (2003) for a good discussion of calibrating the objective function and the interest rate smoothing parameter in particular.
} 
than 87 percent. Importantly, the volatility of the output gap is also reduced by 30 percent. Strict PLT minimizes the social loss function. ${ }^{22}$

If the share of backward-looking agents is 50 percent, strict PLT remains the first-best option (Panel B, appendix Figure A1). The volatility of the output gap is now increasing in the adjustment factor $(\delta)$ and the response of the interest rate to the price level gap $\left(\rho_{p}\right)$. In addition, the volatility of inflation rises for all possible policy regimes. As the share of backward-looking agents rises, PLT continues to minimize the volatility of inflation - the isoloss map $\mathcal{L}_{\pi}$ continues shifting up — and the isoloss map $\mathcal{L}_{x}$ becomes increasingly steeper. If sufficiently many agents are backward-looking (i.e., $\theta_{1}$ and $\theta_{2}$ are low), the increased volatility of the output gap outweighs gains in reducing the volatility of inflation, so IT begins to dominate PLT.

Adding interest rate smoothing (Panel C, appendix Figure A1) shifts the isoloss maps $\mathcal{L}_{\pi}$ and $\mathcal{L}_{x}$ down and makes them flatter. Generally, the larger is $\rho_{i}$, the flatter and lower are the isoloss maps $\mathcal{L}_{\pi}$ and $\mathcal{L}_{x}$.

To complete the picture, we present isoloss maps for cases when potential output $y^{*}$ is perfectly observed by the public and the central banker (Panel D, appendix Figure A1), and when $y^{*}$ is not observed by either of the parties (Panel E, appendix Figure A1). With either full information or symmetric beliefs about potential output, PLT still dominates IT. In the former case there is a trade-off between inflation volatility and output volatility, with PLT increasing the volatility of output. ${ }^{23}$ Hence, in contrast to the baseline case, IT may perform better if there are

\footnotetext{
${ }^{22}$ PLT does not achieve these results by increasing the volatility of the interest rate. The volatility of the interest rate, as measured by the present value of the squared deviations of the interest rate from its steady state level, is also minimized by strict PLT.

${ }^{23}$ Note that temporary i.i.d. shocks to the Phillips curve exogenously increase inflation, and the adjustment to permanent shocks is instantaneous. Hence, the volatility of output is higher under PLT because PLT has to generate
} 
different weights in the loss function. When the central banker does not enjoy an informational advantage (Panel E), partial PLT minimizes the variance of output. Further sensitivity analysis indicates that qualitative conclusions are insensitive to changes in the parameters $\sigma, \Lambda, \sigma_{P}^{2} / \sigma_{T}^{2}$ (see Panels F-H, appendix Figure A1).

The key ingredient in PLT dominating IT is the expectations about the future path of the policy instrument. Woodford (2003, p. 587) notes, “... in the presence of forward-looking privatesector behavior, the central bank mainly affects the economy though changes in expectations about the future path of its instrument; a predictable adjustment of interest rates later, once the disturbances substantially affect inflation and output, should be just as effective in restraining private-sector spending and pricing decisions as an immediate preemptive increase in overnight interest rates." Our findings are consistent with Woodford's observation. Although the immediate response of interest rates is to stimulate output, the subsequent response is to slow down output growth. The larger the share of backward-looking agents, the less attractive PLT is. Once forwardlooking behavior of agents is turned off $(\theta \approx 0)$, IT is superior to PLT. Backward-looking expectations cannot be anchored by promising a future path of interest rates. Because PLT requires prices returning to a starting level through unpleasant deflations following any inflation above target, PLT thus destabilizes the economy when expectations are backward-looking. Additionally, Woodford (2003) argues that history dependence embodied in interest rate smoothing is critical for the optimality of interest rate rules. Here, even if there is no interest rate smoothing, a Taylor-type rule with PLT is history dependent.

A more technical channel of PLT's dominance is the magnitude of the long-run responses to the output gap and inflation. Provided that $\rho_{i}$ and $\delta$ are less than one, our generalized Taylor rule 
in (9) implies that the long-run response of the nominal interest rate to inflation is $\left(\frac{\rho_{\pi}}{1-\rho_{i}}+\frac{\rho_{p}}{\left(1-\rho_{i}\right)(1-\delta)}\right)$,

while the long-run response to the output gap is $\frac{\rho_{x}}{1-\rho_{i}}$. Hence, interest rate smoothing and PLT make long-run responses more aggressive. This finding is consistent with previous studies (e.g., Ehrmann and Smets, 2003) that suggest an aggressive response to inflation under IT if potential output is not observed perfectly. The literature, however, has focused only on increasing $\rho_{\pi}$ or $\rho_{i}$ in the Taylor rule. We identify PLT as another, potentially superior, policy for reducing the volatility of inflation and, in some cases, the output gap. Note that under IT $\left(\rho_{p}=0, \delta=0\right)$, the ratio of short-run to long-run responses to the output gap and inflation is fixed at $\left(1-\rho_{i}\right)^{-1}$. Combined with interest rate smoothing, PLT has more degrees of freedom thus relaxing this constraint and improving social welfare.

The simulations show that the gain from PLT can be substantial even when agents care about inflation, not the price level. These results are consistent with previous work (e.g., Goodfriend and King, 1997, Woodford, 2003, among many others) showing that PLT and other regimes with a nominal level anchor can outperform IT in perfect information economies. We contribute to this literature by demonstrating that PLT can dominate IT in economies with imperfect, possibly asymmetric information, specifically when potential output is not observable. 


\section{References}

Aoki, K., 2003, On optimal monetary policy response to noisy indicators, Journal of monetary economics 50, 501-523.

Ball, L. and R.R. Tchaidze, 2002, Monetary policy rules in practice, American economic association papers and proceedings 92, 108-114.

Ball, L., N.G. Mankiw, and R. Reis, 2005, Monetary policy for inattentive economies, Journal of monetary economics $52,703-725$.

Basu, S., J.G. Fernald, and M.D. Shapiro, 2001, Productivity growth in the 1990s: Technology, utilization, or adjustment? Carnegie-Rochester conference series on public policy 55, 117 165

Bernanke, B.S. and I. Mihov, 1998, Measuring monetary policy, Quarterly journal of economics $113,869-902$.

Blank, R. and M.D. Shapiro, 2001, Labor and the sustainability of output and productivity growth, in: A. Kruger and R.M. Solow, eds., The roaring nineties, (Russell Sage Foundation, New York) 309-366.

Clarida, R., J. Gali, and M. Gertler, 1999, The science of monetary policy: A new Keynesian perspective, Journal of economic literature 37, 1661-1707.

Clarida, R., J. Gali, and M. Gertler, 2000, Monetary policy rules and macroeconomic stability: Evidence and some theory, Quarterly journal of economics 115, 147-80.

Cukierman, A. and F. Lippi, 2005, Endogenous monetary policy with unobserved potential output, Journal of economic dynamics and control 29, 1951-1983.

Ehrmann, M. and F. Smets, 2003, Uncertain potential output: Implications for monetary policy, Journal of economic dynamics and control 27, 1611-1638. 
Erceg, C.J. and A.T. Levin, 2002, Optimal monetary policy with durable and non-durable goods, European Central Bank Working Paper 179.

Friedman, B.M., 1999, Comment, in: J.B. Taylor, ed., Monetary policy rules, (University of Chicago Press, Chicago) 398-402.

Friedman, B.M. and K.N. Kuttner, 1996, A price target for U.S. monetary policy? Lessons from the experience with money growth targets, Brookings papers on economic activity 1, 77-146.

Goodfriend, M. and R.G. King, 1997, The new neoclassical synthesis and the role of monetary policy, in: B.S. Bernanke and J.J. Rotemberg, eds., NBER macroeconomics annual 1997 (MIT Press, Cambridge and London) 231-283.

Greenspan, A., 2004, Risk and uncertainty in monetary policy, American economic association papers and proceedings $94,33-40$.

Gürkaynak, R.S., B. Sack and E. Swanson, 2003, The excess sensitivity of long-term interest rates: Evidence and implications for macroeconomic models. mimeo.

Gürkaynak, R.S., B. Sack and E. Swanson, 2005, The excess sensitivity of long-term interest rates: Evidence and implications for macroeconomic models, American economic review 95, 425436.

Jorgenson, D.W., and K.J. Stiroh, 2000, Raising the speed limit: U.S. economic growth in the information age, Brookings papers of economic activity 1, 125-211.

Kilian, L., 1998, Small-sample confidence intervals for impulse response functions, Review of economics and statistics 80, 218-230.

Krane, S., 2003, An evaluation of real GDP forecast: 1996-2001, Economic perspectives, Federal Reserve Bank of Chicago 1, 2-21

Krueger, A.B. and R.M. Solow, 2001, The roaring nineties: Can full employment be sustained? (Russell Sage Foundation, New York). 
Levin, A.T. and J.C. Williams, 2003, Robust monetary policy with competing reference models, Journal of monetary economics 50, 945-975.

Levin, A., V. Wieland, and J.C. Williams, 1999, Robustness of simple monetary policy rules under model uncertainty, in: J.B. Taylor, ed., Monetary policy rules (University of Chicago Press, Chicago) 263-299.

Levin, A., V. Wieland, and J.C. Williams, 2003, Performance of forecast-based monetary policy rules under model uncertainty, American economics review 93, 622-645.

Lewis, A.D., 2003. A mathematical approach to classical control. Preprint.

Mankiw, N.G., and M.D. Shapiro, 1986, News or noise: An analysis of GNP revisions, Survey of Current Business 66(5), 20-25.

Mankiw, N.G., 2002, U.S. monetary policy during the 1990s, in: J. Frankel and P. Orszag, eds., American economic policy in the 1990s (MIT Press, Cambridge).

Meyer, L.H., 2004, A term at the Fed (HarperCollins Publishers, New York).

Muth, J.F., 1960, Optimal properties of exponentially weighted forecasts, Journal of the American statistical association 55, 299-306.

Neuendorf, K.A., 2002, The content analysis guidebook (Sage Publications, Thousand Oaks, CA).

Oliner, S.D., and D.E. Sichel, 2000, The resurgence of growth in the late 1990s: Is information technology the story? Journal of economic perspectives 14, 3-22.

Orphanides, A. and S. van Norden, 2002, The unreliability of output-gap estimates in real time, Review of economics and statistics $84,569-583$.

Phillips, A.W., 1954, Stabilization policy in a closed economy, Economic journal 64, 290-323.

Phillips, A.W., 1957, Stabilization policy and the time-forms of lagged responses, Economic journal $67,265-277$.

Roberts, J.M., 1995, New Keynesian economics and the Phillips curve, Journal of money, credit and banking 27, 975-984. 
Rudebusch, G., 2002, Term structure evidence on interest rate smoothing and monetary policy inertia, Journal of monetary economics 49, 1161-1187.

Shiller, R.J., 1997, Why do people dislike inflation? In: C.D. Romer and D. Romer, eds., Reducing inflation, (University of Chicago Press, Chicago).

Staiger, D., J.H. Stock and M.W. Watson, 1997, The NAIRU, unemployment, and monetary policy, Journal of economic perspectives 11, 33-49.

Staiger, D., J.H. Stock and M.W. Watson, 2001, Prices, wages, and the U.S. NAIRU in the 1990s, in: A. Kruger and R.M. Solow, eds., The roaring nineties, (Russell Sage Foundation, New York) 3-60.

Stock, J.H., J.H. Wright, and M. Yogo, 2002, A survey of weak instruments and weak identification in generalized method of moments, Journal of business and economic statistics 20, 518-520.

Svensson, L.O.E., 1999. Price level targeting vs. inflation targeting: A free lunch? Journal of money, credit, and banking 31, 277-295.

Svensson, L.O.E. and M. Woodford, 2003, Indicator variables for optimal policy, Journal of monetary economics 50, 691-720.

Taylor, J.B., 1993, Discretion versus policy rules in practice, Carnegie-Rochester conference series on public policy $39,195-214$.

Tobin, J., 1984, Overview, in: Federal Reserve Bank of Kansas City, New challenges for monetary policy: Symposium on sponsored by the Federal Reserve Bank of Kansas city at Jackson Hole, Wyoming, 27 August 1982.

Woodford, M., 2003, Interest and prices (Princeton University Press, Princeton NJ). 
Table 1. GDP growth and inflation rates: Forecast errors

(Percent change, fourth quarter to fourth quarter)

\begin{tabular}{lccccc}
\hline & 1996 & 1997 & 1998 & 1999 & 2000 \\
\hline GDP growth rate & & & & & \\
$\quad$ Blue Chip & 1.1 & 1.8 & 2.2 & 1.8 & 0.2 \\
$\quad$ Survey of Professional Forecasters & 1.1 & 1.4 & 2.1 & 1.7 & 0.3 \\
& & & & & \\
$\quad$ & & & & & \\
$\quad$ Inflation rate & -0.7 & -0.7 & -1.1 & -0.1 & 0.6 \\
$\quad$ Blue Chip & -0.7 & -0.7 & -1.2 & 0.1 & 0.5 \\
$\quad$ Survey of Professional Forecasters & -0.8 & -0.6 & -1.3 & -0.1 & -0.1 \\
$\quad$ Simple Phillips curve & & & & & \\
\hline
\end{tabular}

Notes: Forecast errors are computed as the actual minus forecasted value of the variable for the year indicated. The forecasts are produced at the beginning of the year. Inflation rate is computed based on the GDP deflator. Source: Blue Chip Economic Indicators, Survey of Professional Forecasters, and authors' calculations. The Phillips curve forecasts are computed by the authors and are also reported in Figure 1. 
Table 2. Estimates of the generalized Taylor rule: Restricted specification

\begin{tabular}{lcc}
\hline \multicolumn{1}{c}{$\begin{array}{c}\text { Parameter } \\
(1)\end{array}$} & $1955-1979$ & $1982-2003$ \\
& 0.043 & $(2)$ \\
\hline Price level gap, $\rho_{p}$ & $(0.043)$ & 0.369 \\
& 0.135 & $0.072)$ \\
Inflation, $\rho_{\pi}$ & $(0.109)$ & $(0.097)$ \\
& 0.294 & 0.778 \\
Output gap, $\rho_{x}$ & $(0.070)$ & $(0.204)$ \\
& 0.364 & 0.814 \\
Adjustment factor, $\delta$ & $(0.124)$ & $(0.027)$ \\
& 0.736 & 0.177 \\
Interest rate smoothing, $\rho_{i}$ & $(0.102)$ & $(0.105)$ \\
& 0.652 & 0.621 \\
\hline S.E.E. & 0.270 & 0.117 \\
P-value for restriction & & \\
\hline
\end{tabular}

Notes: The dependent variable is federal funds rate. Estimates are from two-step GMM using quarterly data. Instruments include four lags of the output gap, inflation, federal funds rate, and log commodity price index. A constant is included but not reported. HAC standard errors are in parentheses. P-value is for the test of the restriction on the coefficients in equation (14). 
Table 3. Estimates of the Taylor rules: Restricted versus unrestricted specifications

\begin{tabular}{|c|c|c|c|c|c|c|c|}
\hline \multirow[t]{2}{*}{ Variables } & \multicolumn{2}{|c|}{$\begin{array}{c}\text { Unrestricted specification, } \\
\text { eq. (15) }\end{array}$} & \multicolumn{3}{|c|}{$\begin{array}{c}\text { Restricted specification, } \\
\text { eq. (14) }\end{array}$} & \multicolumn{2}{|c|}{$\begin{array}{c}\text { Clarida, Gali and Gertler (2000), } \\
\text { eq. (13) }\end{array}$} \\
\hline & $1955-1979$ & $1982-2003$ & Parameters & $1955-1979$ & $1982-2003$ & 1955-1979 & $1982-2003$ \\
\hline$(1)$ & $(2)$ & (3) & (4) & $(5)$ & $(6)$ & $(7)$ & $(8)$ \\
\hline \multirow[t]{2}{*}{ current inflation, $\pi_{t}$} & 0.004 & 0.051 & $\rho_{\pi}$ & 0.135 & 0.185 & 0.169 & 0.209 \\
\hline & $(0.058)$ & $(0.107)$ & & $(0.109)$ & $(0.097)$ & $(0.055)$ & $(0.079)$ \\
\hline \multirow[t]{2}{*}{ lagged inflation, $\pi_{t-1}$} & 0.046 & 0.176 & $\rho_{p}-\rho_{\pi} \delta$ & -0.006 & 0.218 & & \\
\hline & $(0.040)$ & $(0.061)$ & & $(0.066)$ & $(0.106)$ & & \\
\hline \multirow{2}{*}{ current output gap, $x_{t}$} & 0.407 & 0.760 & $\rho_{x}$ & 0.294 & 0.778 & 0.219 & 0.121 \\
\hline & $(0.114)$ & $(0.185)$ & & $(0.070)$ & $(0.204)$ & $(0.051)$ & $(0.051)$ \\
\hline \multirow[t]{2}{*}{ lagged output gap, $x_{t-1}$} & -0.258 & -0.559 & $-\rho_{x} \delta$ & -0.107 & -0.633 & & \\
\hline & $(0.087)$ & $(0.148)$ & & $(0.118)$ & $(0.029)$ & & \\
\hline \multirow[t]{2}{*}{$1^{\text {st }}$ lag of federal funds } & 1.196 & 0.948 & $\delta+\rho_{i}$ & 1.100 & 0.991 & 0.969 & 1.167 \\
\hline & $(0.083)$ & $(0.106)$ & & $(0.145)$ & $(0.108)$ & $(0.103)$ & $(0.096)$ \\
\hline \multirow[t]{2}{*}{$2^{\text {nd }}$ lag of federal funds } & -0.230 & 0.010 & $-\delta \rho_{i}$ & -0.268 & -0.144 & -0.180 & -0.241 \\
\hline & $(0.080)$ & $(0.108)$ & & $(0.092)$ & $(0.085)$ & $(0.073)$ & $(0.097)$ \\
\hline S.E.E. & 0.697 & 0.627 & & 0.652 & 0.621 & 0.655 & 0.622 \\
\hline
\end{tabular}

Note: The dependent variable is federal funds rate. Estimates are based on quarterly data. Column (1) gives the right-hand-side variables.

Columns (2)-(8) are estimated by two-step GMM. Instruments include four lags of the output gap, inflation, federal funds rate, and log commodity price index. A constant is included but not reported. HAC standard errors are in parentheses. Standard errors in columns (5) and (6) are computed by the delta method. The overidentifying restriction test cannot reject validity of instruments at any reasonable significance level. 
Table 4. Content analysis: "Inflation" versus "price level" in the rhetoric of central bankers.

\begin{tabular}{|c|c|c|c|}
\hline \multicolumn{4}{|c|}{ Panel A: descriptive statistics } \\
\hline Central Banker & $\begin{array}{l}\text { Mean } \\
\text { frequency of } \\
\text { words }\end{array}$ & $\begin{array}{c}\text { Standard } \\
\text { error }\end{array}$ & $\begin{array}{l}\text { Number } \\
\text { of texts }\end{array}$ \\
\hline$(1)$ & $(2)$ & (3) & $(4)$ \\
\hline \multicolumn{4}{|c|}{ Inflation words, percent of total words } \\
\hline Bernanke & 1.377 & 0.269 & 16 \\
\hline Blinder & 0.787 & 0.229 & 8 \\
\hline Greenspan & 0.378 & 0.055 & 24 \\
\hline \multicolumn{4}{|c|}{ Price level words, percent of total words } \\
\hline Bernanke & 0.754 & 0.186 & 16 \\
\hline Blinder & 0.546 & 0.164 & 8 \\
\hline Greenspan & 0.723 & 0.155 & 24 \\
\hline \multicolumn{4}{|c|}{ Difference: Inflation minus price level } \\
\hline Bernanke & 0.623 & 0.297 & 16 \\
\hline Blinder & 0.241 & 0.186 & 8 \\
\hline Greenspan & -0.344 & 0.155 & 24 \\
\hline
\end{tabular}

Panel B: Difference-in-differences estimator

\begin{tabular}{lccc} 
& Coefficient & $\begin{array}{c}\text { Standard } \\
\text { error }\end{array}$ & p-value \\
\hline Bernanke & 0.974 & 0.345 & 0.007 \\
Blinder & 0.598 & 0.214 & 0.008 \\
$\mathrm{R}^{2}$ & 0.20 & & \\
\hline \hline
\end{tabular}

Note. Panel A: Frequency is in percent of total words in a given text. The standard error is for the mean. Panel B: The dependent variable in the estimated regressions is the relative propensity to mention inflation, which is defined as the frequency of inflation words minus the frequency of price level words. A constant is included but not reported. The omitted category is Alan Greenspan. The regression estimates are weighted least squares to take into account the heteroskedasticity arising because the articles have different numbers of words. 
Figure 1. Inflation rate: Actual and forecasted

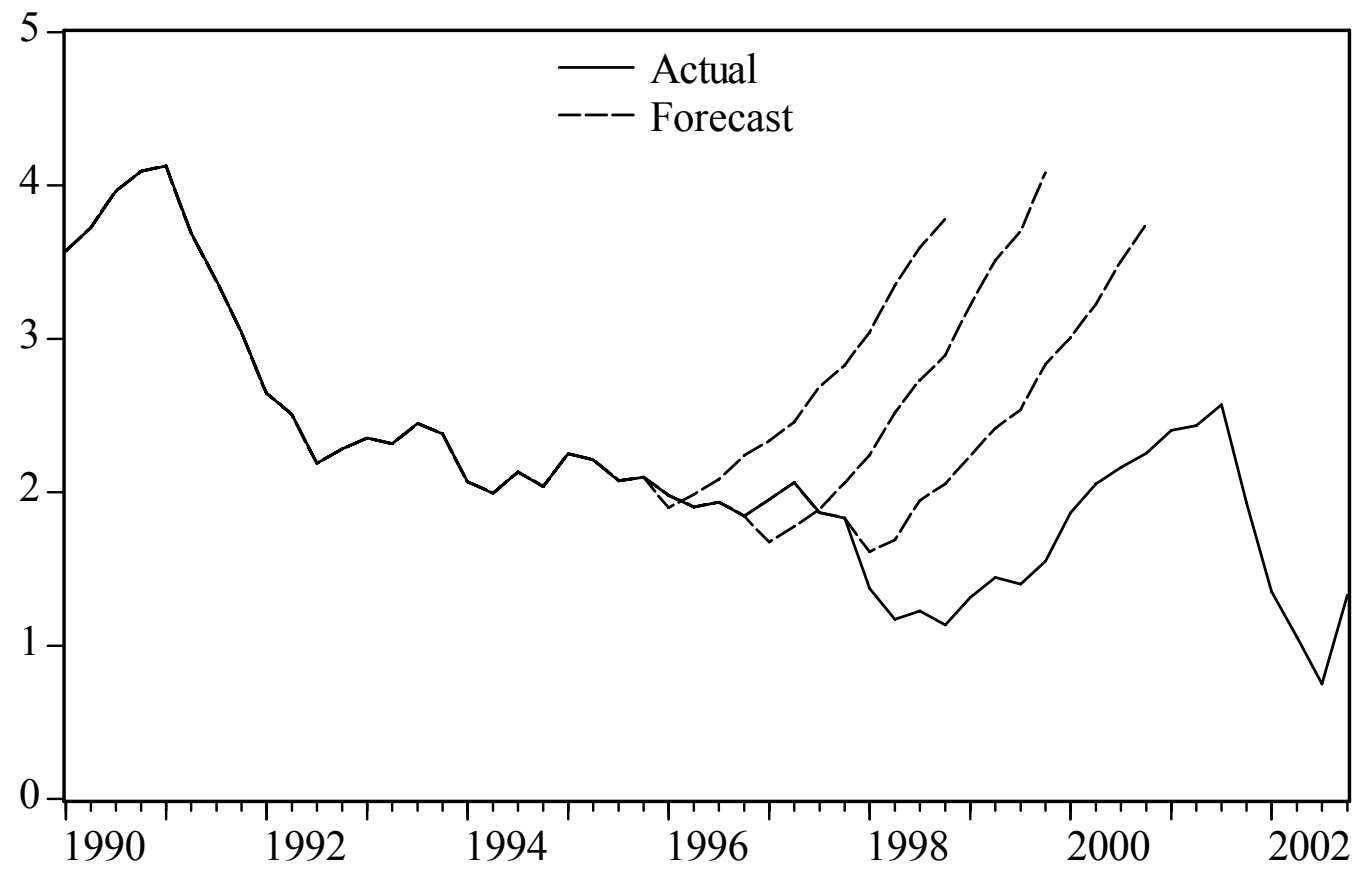

Notes: Solid line is the actual inflation rate (four-quarter percent change in GDP deflator), dashed line is its forecast based on a backward-looking Phillips curve. The Phillips curve includes four lags of the inflation rate and the deviation of unemployment rate (quarterly average) from the NAIRU. The inflation rate is forecasted dynamically. The forecasts use the deviation of actual unemployment rate from a NAIRU estimate as of the beginning of the period. 
Figure 2. Federal funds rate: Actual and forecasted by the Taylor rule

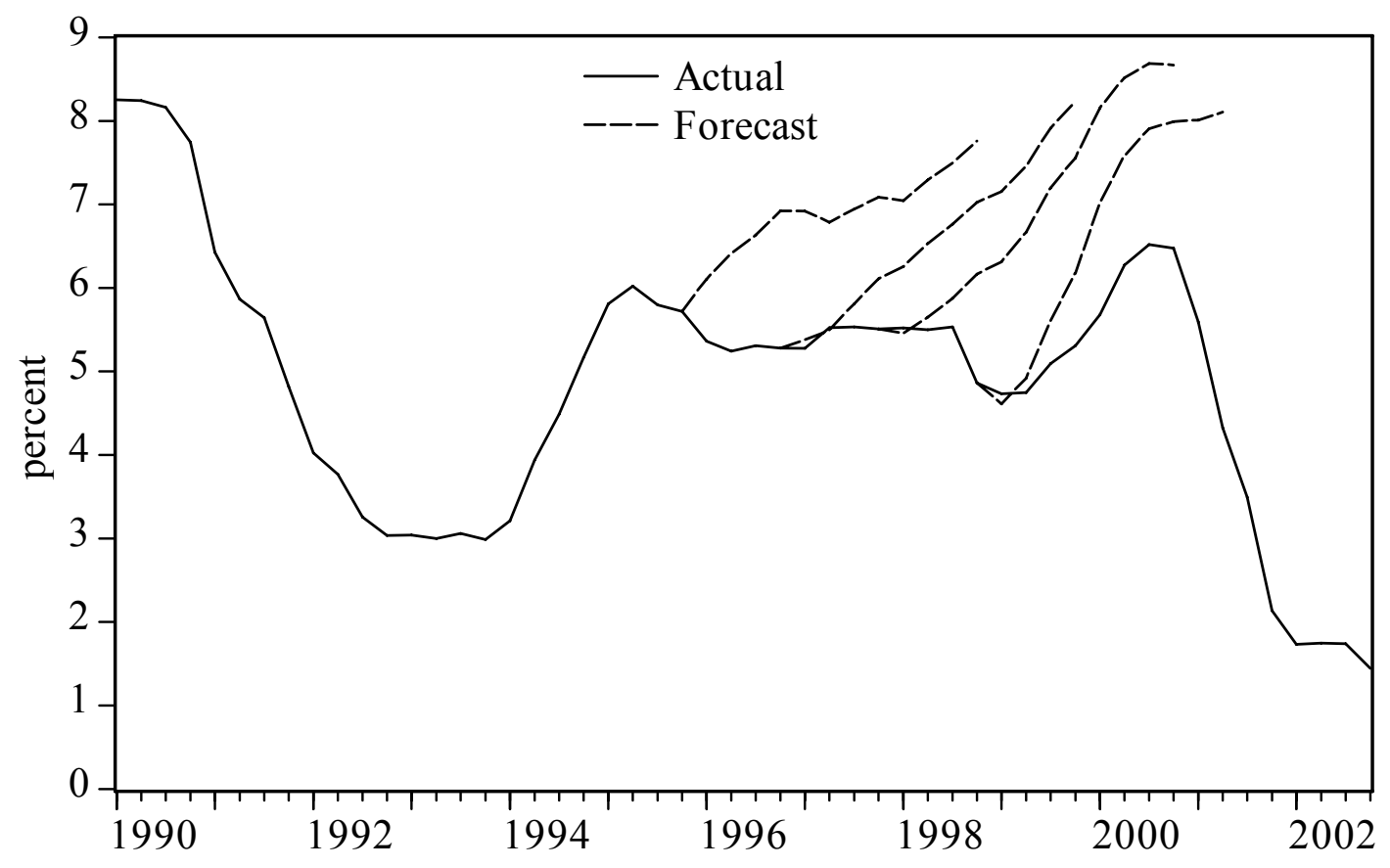

Notes: Solid line is the actual federal funds rate and the dashed line is the predicted value from the Taylor rule. The Taylor rule includes the current unemployment rate, inflation rate (GDP deflator), and two lags of the federal funds rate. Predictions are as of 1995:Q4, 1996:Q4, 1997:Q4, and 1998:Q4. These predictions use actual inflation and unemployment rates and the dynamic forecast of the federal funds rate based on the Taylor rule. The rule is estimated by two-step GMM over the period from 1984 to the quarter prior to the forecast period. Instruments are lags of the inflation rate, unemployment rate, federal funds rate, and log commodity price index. 
Figure 3. Simulated impulse responses to a permanent one percent increase in potential output (baseline case)
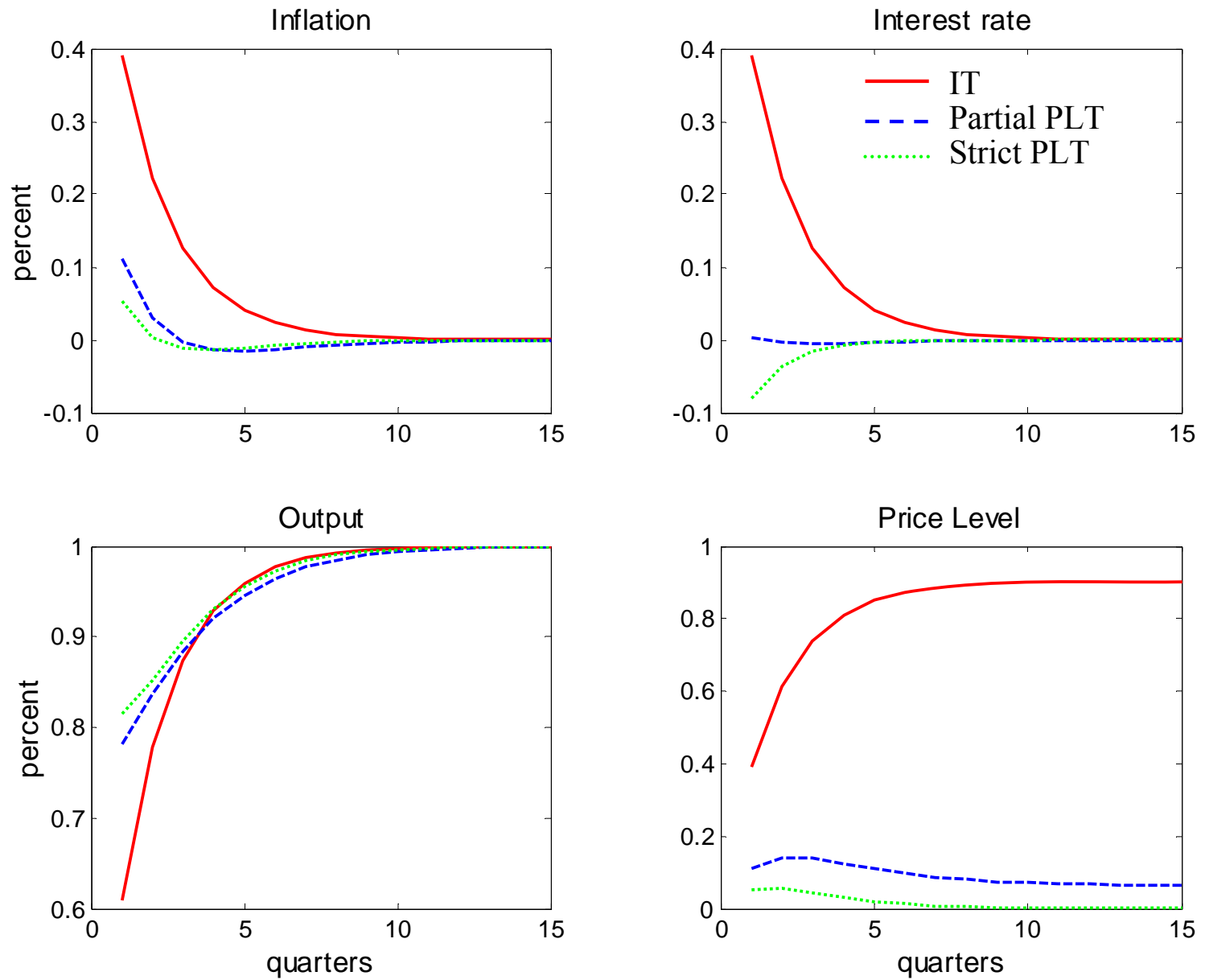

Notes: The figure shows percent deviations from steady state. All parameters are set at their baseline values. The central banker believes that potential output has increased while the public does not share this belief. Solid line is IT ( $\left.\delta=0, \rho_{\pi}=2, \rho_{p}=0\right)$, dashed line is partial PLT $\left(\delta=0.9, \rho_{\pi}=1, \rho_{p}=1\right)$, and dotted line is strict PLT $\left(\delta=1, \rho_{\pi}=0, \rho_{p}=2\right)$. See text for details of parameter values. 
Figure 4. Simulated impulse responses to a permanent one percent increase in potential output (fraction of agents is backward-looking)
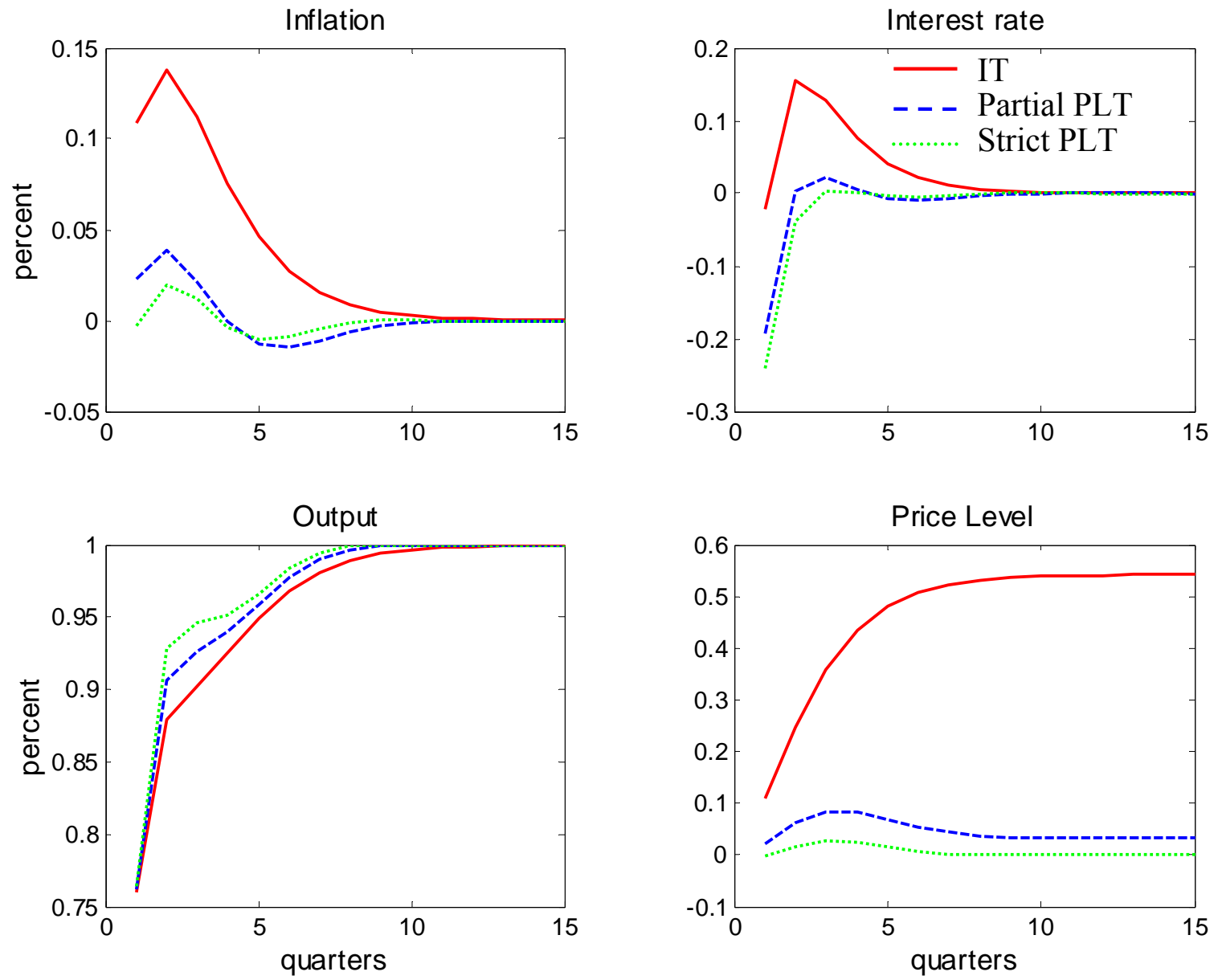

Notes: The figure shows percent deviations from steady state. The share of backward-looking agents is $\theta_{1}=\theta_{2}=50 \%$. Other parameters are set at their baseline values. The central banker believes that potential output has increased while the public does not share this belief. Solid line is IT ( $\left.\delta=0, \rho_{\pi}=2, \rho_{p}=0\right)$, dashed line is partial PLT $\left(\delta=0.9, \rho_{\pi}=1, \rho_{p}=1\right)$, and dotted line is strict PLT $\left(\delta=1, \rho_{\pi}=0, \rho_{p}=2\right)$. See text for details of the parameter values. 
Figure 5. Simulated impulse responses to a permanent one percent increase in potential output (interest rate smoothing)
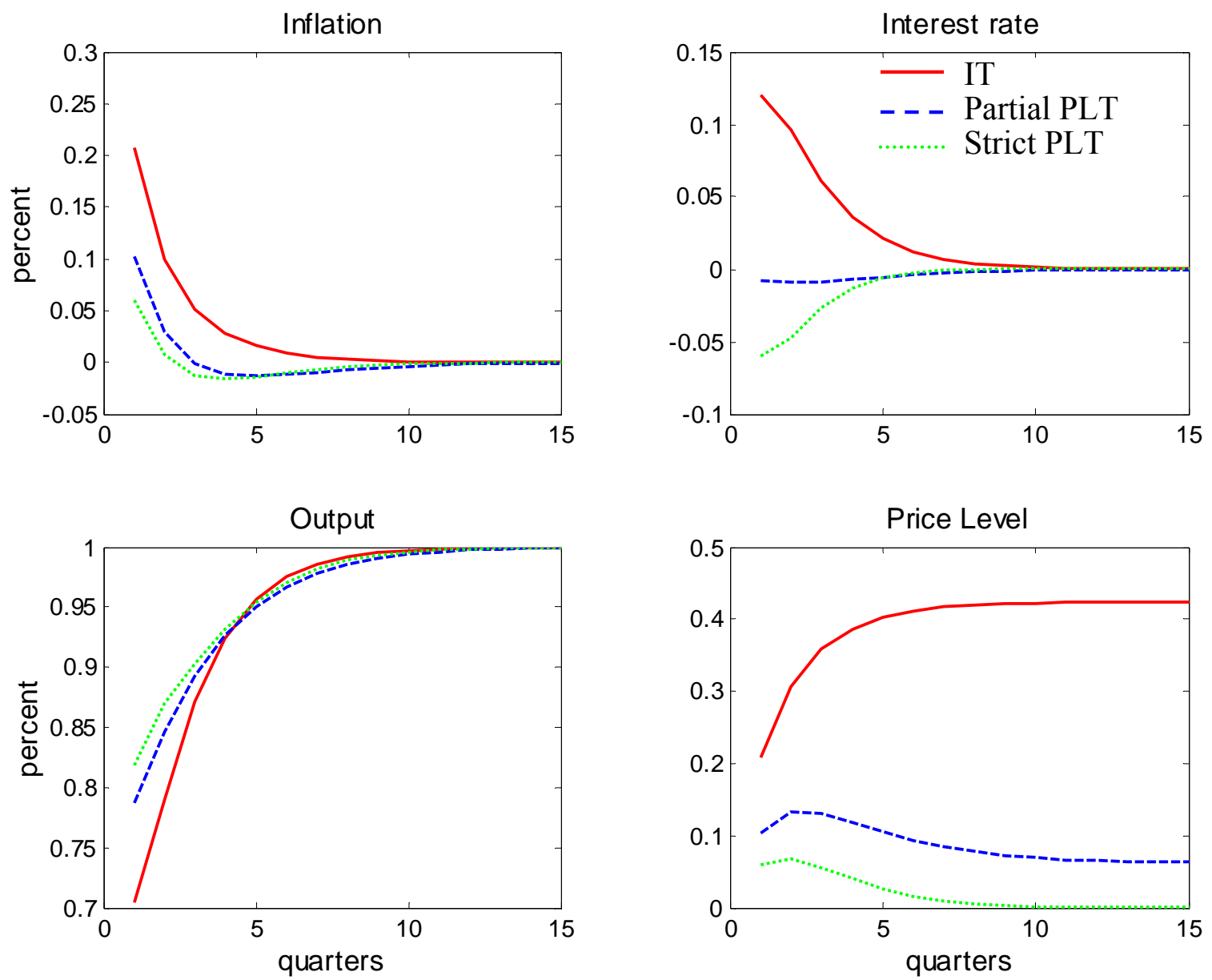

Notes: The figure shows percent deviations from steady state. The interest rate smoothing parameter is $\rho_{i}=0.9$. Other parameters are set at their baseline values. The central banker believes that potential output has increased while the public does not share this belief. Solid line is IT ( $\left.\delta=0, \rho_{\pi}=2, \rho_{p}=0\right)$, dashed line is partial PLT $\left(\delta=0.9, \rho_{\pi}=1, \rho_{p}=1\right)$, and dotted line is strict PLT ( $\left.\delta=1, \rho_{\pi}=0, \rho_{p}=2\right)$. See text for details of the parameter values. 
Figure 6. Estimated impulse response of the consumer price index to 0.1 percent inflation surprise

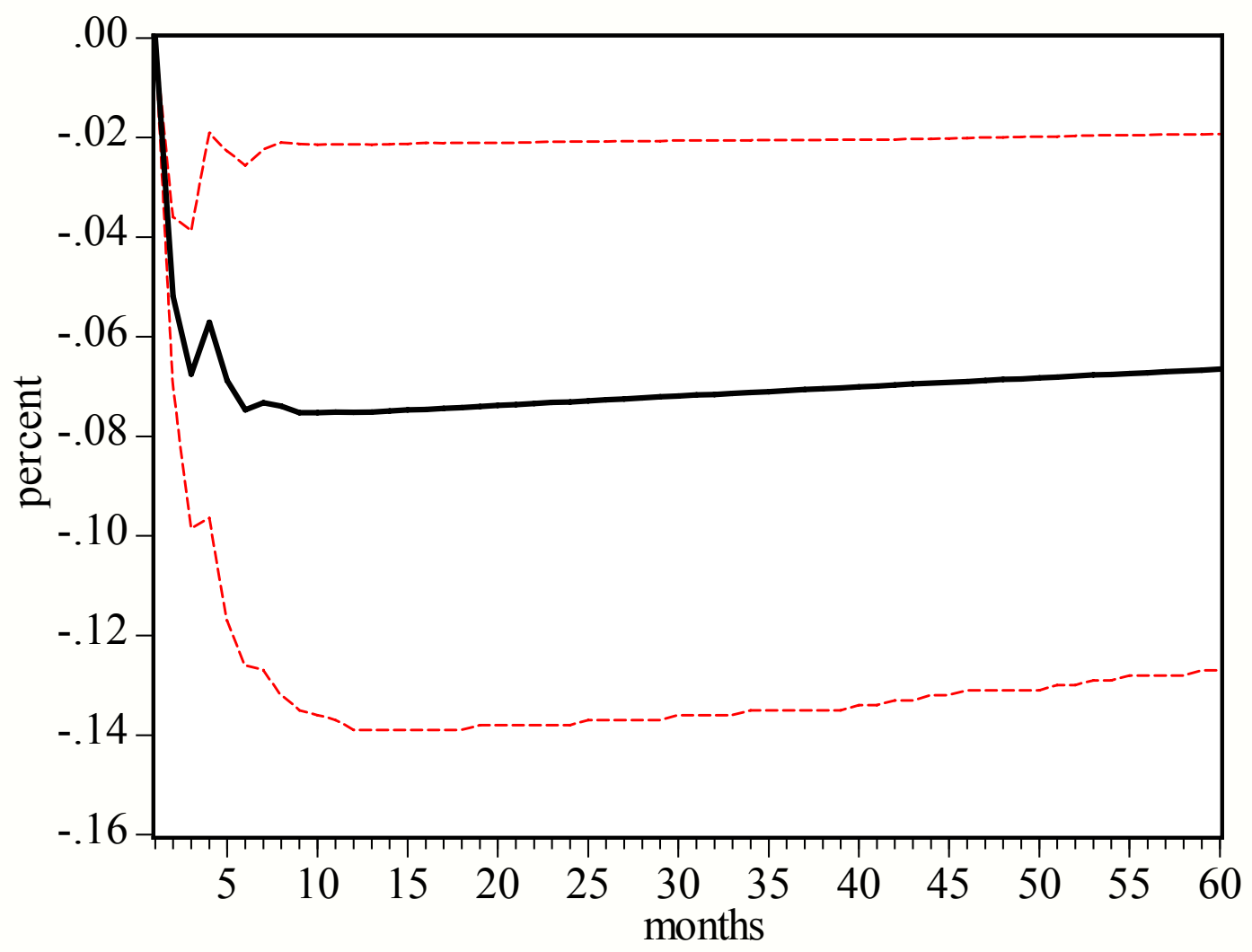

Note: The impulse response is computed from a $\operatorname{VAR}(4)$ that includes log consumer price index and CPI inflation announcement surprises. Dashed lines are Kilian's (1998) bootstrap-withinbootstrap 95 percent confidence bounds (2,000 replications). 


\begin{tabular}{|c|c|c|c|c|c|}
\hline \multirow[b]{2}{*}{ Speech/Paper/Book } & \multirow[b]{2}{*}{ Date } & \multirow[b]{2}{*}{ Place } & \multirow[b]{2}{*}{ Words } & \multicolumn{2}{|c|}{ Frequency index } \\
\hline & & & & $\begin{array}{l}\text { Price } \\
\text { Level } \\
\end{array}$ & Inflation \\
\hline \multicolumn{6}{|c|}{ Alan Greenspan } \\
\hline Price measurement & $11 / 7 / 1997$ & Center for Financial Studies, Frankfurt, Germany & 3,919 & 3.04 & 0.56 \\
\hline Inaugural speech for economic seminar series & $10 / 14 / 1997$ & U. of Connecticut, Storrs, Connecticut & 3,225 & 0.03 & 0.00 \\
\hline Globalization of Finance & $10 / 14 / 1997$ & Cato Institute, Washington, D.C. & 2,856 & 0.14 & 0.14 \\
\hline Rules vs. discretionary monetary policy & 9/5/1997 & Stanford U., Stanford, CA & 4,081 & 1.30 & 0.49 \\
\hline Current monetary policy & $5 / 8 / 1997$ & The Stern School of Business, New York University, NY & 2,401 & 0.21 & 1.04 \\
\hline Central Banking and Global Finance & $1 / 14 / 1997$ & Catholic University Leuven, Leuven, Belgium & 5,022 & 0.48 & 0.48 \\
\hline Question: Is There a New Economy? & $9 / 4 / 1998$ & U. of California, Berkeley, CA & 5,212 & 0.35 & 0.17 \\
\hline Problems of Price Measurement & $1 / 3 / 1998$ & AEA Annual Meeting, Chicago, IL & 3,789 & 3.11 & 0.48 \\
\hline Information, productivity, and capital investment & $10 / 28 / 1999$ & Business Council, Boca Raton, FL & 3,072 & 0.29 & 0.23 \\
\hline The American economy in a world context & 5/6/1999 & FRB Chicago, Chicago, IL & 4,571 & 0.68 & 0.04 \\
\hline Challenges for monetary policymakers & $10 / 19 / 2000$ & Cato Institute, Washington, D.C. & 2,943 & 1.02 & 0.31 \\
\hline Technology innovation and its economic impact & $4 / 7 / 2000$ & National Technology Forum, St. Louis, Missouri & 2,087 & 0.19 & 0.34 \\
\hline Technological innovation and the economy & $4 / 5 / 2000$ & White House Conference on the New Economy, Washington, D.C. & 2,701 & 0.63 & 0.48 \\
\hline Technology and the economy & $1 / 13 / 2000$ & Economic Club of New York, NY & 4,580 & 0.31 & 0.28 \\
\hline Transparency in monetary policy & $10 / 11 / 2001$ & FRB St. Louis & 1,460 & 1.85 & 0.27 \\
\hline Economic developments & $5 / 24 / 2001$ & Economic Club of New York, NY & 3,889 & 0.72 & 0.28 \\
\hline $\begin{array}{l}\text { The challenge of measuring and modeling a dynamic } \\
\text { economy }\end{array}$ & $3 / 27 / 2001$ & Wash. Econ. Policy Conference of the NABE, Washington, D.C. & 2,556 & 1.17 & 0.08 \\
\hline Issues for Monetary Policy & $12 / 19 / 2002$ & Economic Club of New York, NY & 4,531 & 0.86 & 0.51 \\
\hline The Wealth of Nations Revisited & $11 / 12 / 2002$ & Banco de Mexico, Mexico City, Mexico & 3,113 & 0.03 & 0.51 \\
\hline Productivity & $10 / 23 / 2002$ & $\begin{array}{l}\text { U.S. Dep't of Labor \& American Enterprise Institute Conference, } \\
\text { Washington, D.C. }\end{array}$ & 2,335 & 0.09 & 0.21 \\
\hline Remarks by Chairman Alan Greenspan & $11 / 6 / 2003$ & Securities Industry Association annual meeting, Boca Raton, FL & 2,102 & 0.19 & 0.33 \\
\hline Monetary Policy under Uncertainty & $8 / 29 / 2003$ & FRB Kansas City Conference, Jackson Hole, WY & 1,940 & 0.31 & 0.10 \\
\hline Monetary policy twenty-five years after October 1979 & $10 / 7 / 2004$ & FRB St. Louis & 1,114 & 0.45 & 0.99 \\
\hline Risk and Uncertainty in Monetary Policy & $5 / 1 / 2004$ & AEA Annual Meeting, San Diego, CA & 5,991 & 1.03 & 0.73 \\
\hline
\end{tabular}

(continued on next page) 


\begin{tabular}{|c|c|c|c|c|c|}
\hline \multirow[b]{2}{*}{ Speech/Paper/Book } & \multirow[b]{2}{*}{ Date } & \multirow[b]{2}{*}{ Place } & \multirow[b]{2}{*}{ Words } & \multicolumn{2}{|c|}{ Frequency index } \\
\hline & & & & $\begin{array}{l}\text { Price } \\
\text { Level } \\
\end{array}$ & Inflation \\
\hline \multicolumn{6}{|c|}{ Alan Blinder } \\
\hline Central banking in theory and practice & $1 / 1 / 1998$ & Princeton university press & 50,532 & 0.04 & 0.25 \\
\hline Testimony, Senate Banking Pending Nominations & $5 / 6 / 1994$ & U.S. Senate committee on banking, housing and urban affairs & 2,235 & 1.25 & 1.83 \\
\hline Interview with Alan Blinder & $12 / 1 / 1994$ & FRB Minnesota & 4,218 & 0.28 & 0.31 \\
\hline $\begin{array}{l}\text { Comment on Cecchetti's "Measuring short-run inflation } \\
\text { for central bankers" }\end{array}$ & $5 / 1 / 1997$ & FRB St. Louis Review & 2,659 & 1.20 & 1.39 \\
\hline Summary panel & $11 / 1 / 2000$ & FRB Boston & 3,555 & 0.84 & 1.04 \\
\hline $\begin{array}{l}\text { Commentary: Should the European Central Bank and the } \\
\text { Federal Reserve Be Concerned about Fiscal Policy? }\end{array}$ & $8 / 1 / 2002$ & FRB Kansas Symposium at Jackson Hole, WY & 4,336 & 0.92 & 0.16 \\
\hline Issues in the coordination of monetary and fiscal policy & 9/1/1982 & NBER WP 982 & 11,798 & 0.13 & 0.18 \\
\hline $\begin{array}{l}\text { Central bank credibility: Why do we care? How do we } \\
\text { build it? }\end{array}$ & $6 / 1 / 1999$ & NBER WP 7161 & 6,710 & 0.09 & 1.13 \\
\hline \multicolumn{6}{|c|}{ Ben Bernanke } \\
\hline The Economic Outlook & $3 / 30 / 2005$ & $\begin{array}{l}\text { Redefining Investment Strategy Education Symposium, Dayton, } \\
\text { Ohio }\end{array}$ & 3,281 & 1.22 & 1.49 \\
\hline Productivity & $1 / 19 / 2005$ & U. of Arkansas, Little Rock, Arkansas & 5,052 & 0.06 & 0.24 \\
\hline The Logic of Monetary Policy & $12 / 2 / 2004$ & National Economists Club, Washington, D.C. & 6,183 & 0.05 & 0.39 \\
\hline Oil and the Economy & $10 / 21 / 2004$ & Distinguished Lecture Series, Darton College, Albany, Georgia & 6,434 & 2.81 & 0.96 \\
\hline $\begin{array}{l}\text { Panel discussion: What Have We Learned Since October } \\
\text { 1979? }\end{array}$ & $10 / 8 / 2004$ & FRB St. Louis & 4,175 & 0.17 & 1.87 \\
\hline Central Bank Talk and Monetary Policy & $10 / 7 / 2004$ & Japan Society Corporate Luncheon, NY & 5,131 & 0.29 & 0.27 \\
\hline Gradualism & $5 / 20 / 2004$ & FRB San Francisco \& U. of Washington, Seattle, Washington & 5,410 & 0.22 & 0.55 \\
\hline $\begin{array}{l}\text { Monetary Policy Modeling: Where Are We and Where } \\
\text { Should We Be Going? }\end{array}$ & $3 / 27 / 2004$ & FRB Models and Monetary Policy Conference, Washington, D.C. & 1,950 & 0.51 & 0.92 \\
\hline The Great Moderation & $2 / 20 / 2004$ & Eastern Economic Association, Washington, DC & 6,964 & 0.39 & 1.81 \\
\hline $\begin{array}{l}\text { Conducting Mon. Policy at Very Low Short-Term Interest } \\
\text { Rates }\end{array}$ & $1 / 3 / 2004$ & AEA Meetings, San Diego, CA & 3,944 & 0.35 & 0.18 \\
\hline Panel Discussion & $10 / 17 / 2003$ & FRB St. Louis, St. Louis, Missouri & 2,896 & 0.52 & 3.18 \\
\hline An Unwelcome Fall in Inflation? & $7 / 23 / 2003$ & Economics Roundtable, U. California, San Diego, La Jolla, CA & 6,493 & 0.88 & 3.16 \\
\hline A Perspective on Inflation Targeting & $3 / 25 / 2003$ & Washington Policy Conference of the NABE, Washington, D.C. & 6,322 & 0.87 & 2.91 \\
\hline Some Thoughts on Monetary Policy in Japan & $5 / 31 / 2003$ & Japan Society of Monetary Economics, Tokyo, Japan & 6,299 & 1.73 & 0.78 \\
\hline "Constrained Discretion” and Monetary Policy & $2 / 3 / 2003$ & Money Marketeers of New York University, NY & 6,785 & 1.69 & 2.56 \\
\hline Deflation: Making Sure “It" Doesn’t Happen Here & $11 / 21 / 2002$ & National Economists Club, Washington, D.C. & 6,511 & 0.58 & 0.75 \\
\hline
\end{tabular}

Note: The third column report the number of words in a text. The last two columns report the frequency of price level and inflation words as a percent of total words in a given text. 
Appendix Table A2. Calibration of experiments in welfare simulations.

\begin{tabular}{|c|c|c|c|c|c|c|c|c|}
\hline \multirow[b]{2}{*}{ Panel } & \multirow{2}{*}{ Information structure } & \multicolumn{7}{|c|}{ Parameters } \\
\hline & & $\theta_{1}$ & $\theta_{2}$ & $\rho_{i}$ & $\sigma$ & $\Lambda$ & $\lambda$ & $\sigma_{T}^{2} / \sigma_{P}^{2}$ \\
\hline A & Forward-looking agents & 1.0 & 1.0 & 0.0 & 1.0 & 0.35 & 0.57 & 0.11 \\
\hline B & $\begin{array}{l}\text { Partially backward- } \\
\text { looking agents }\end{array}$ & 0.5 & 0.5 & 0.0 & 1.0 & 0.35 & 0.57 & 0.11 \\
\hline $\mathrm{C}$ & Interest rate smoothing & 1.0 & 1.0 & 0.9 & 1.0 & 0.35 & 0.57 & 0.11 \\
\hline $\mathrm{D}$ & $\begin{array}{l}\text { Potential output is } \\
\text { perfectly observable by } \\
\text { all parties }\end{array}$ & 1.0 & 1.0 & 0.0 & 1.0 & 0.35 & 0.57 & 0.11 \\
\hline $\mathrm{E}$ & $\begin{array}{l}\text { No central banker } \\
\text { informational advantage }\end{array}$ & 1.0 & 1.0 & 0.0 & 1.0 & 0.35 & 0.57 & 0.11 \\
\hline $\mathrm{F}$ & $\begin{array}{l}\text { Sensitivity analysis: } \\
\text { Slope of the Phillips } \\
\text { curve }\end{array}$ & 1.0 & 1.0 & 0.0 & 1.0 & 0.05 & 0.67 & 0.11 \\
\hline G & $\begin{array}{l}\text { Sensitivity analysis: } \\
\text { Slope of the IS curve }\end{array}$ & 1.0 & 1.0 & 0.0 & 2.0 & 0.35 & 0.57 & 0.11 \\
\hline $\mathrm{H}$ & $\begin{array}{l}\text { Sensitivity analysis: } \\
\text { Signal to noise ratio }\end{array}$ & 1.0 & 1.0 & 0.0 & 1.0 & 0.35 & 0.71 & 1.00 \\
\hline
\end{tabular}

Note: Table gives the parameters underlying simulations in appendix Figure A1. Other parameters are fixed across cases: $\rho_{x}=1, \omega_{x}=1, \beta=0.99$. See text for further details. 
Appendix Figure A1. Isoloss maps

Panel A

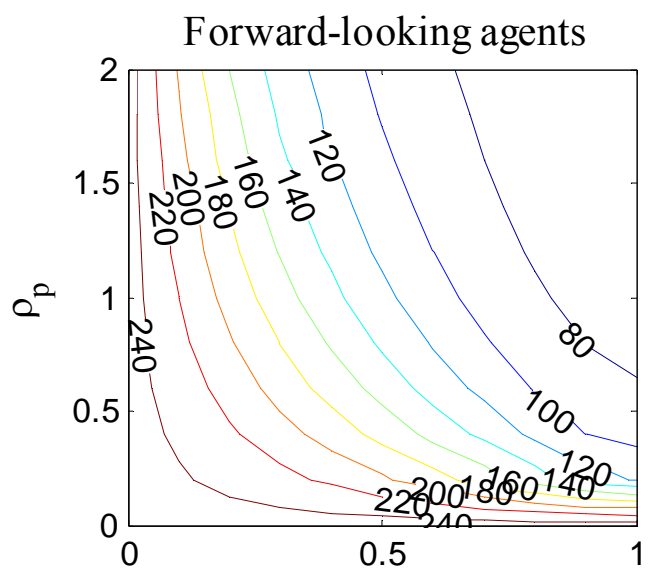

Panel C

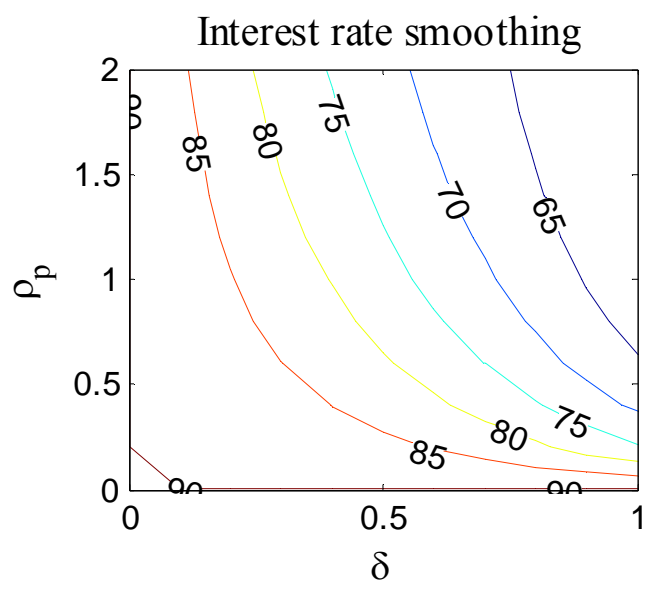

Panel B

Partially backward-looking agents

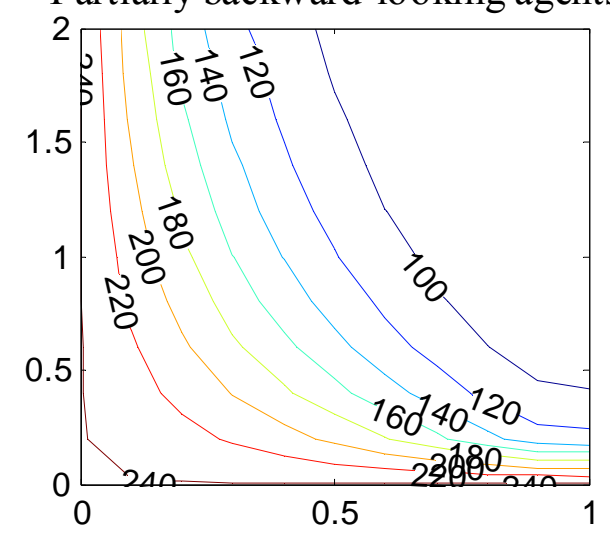

Panel D

Potential is perfectly observable

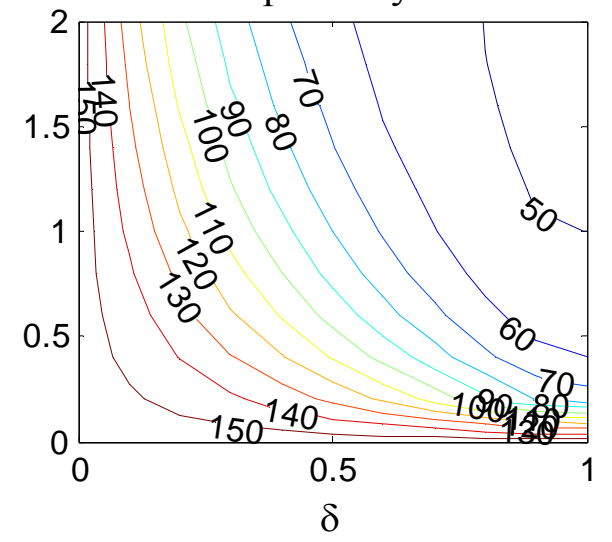

(continued on next page) 

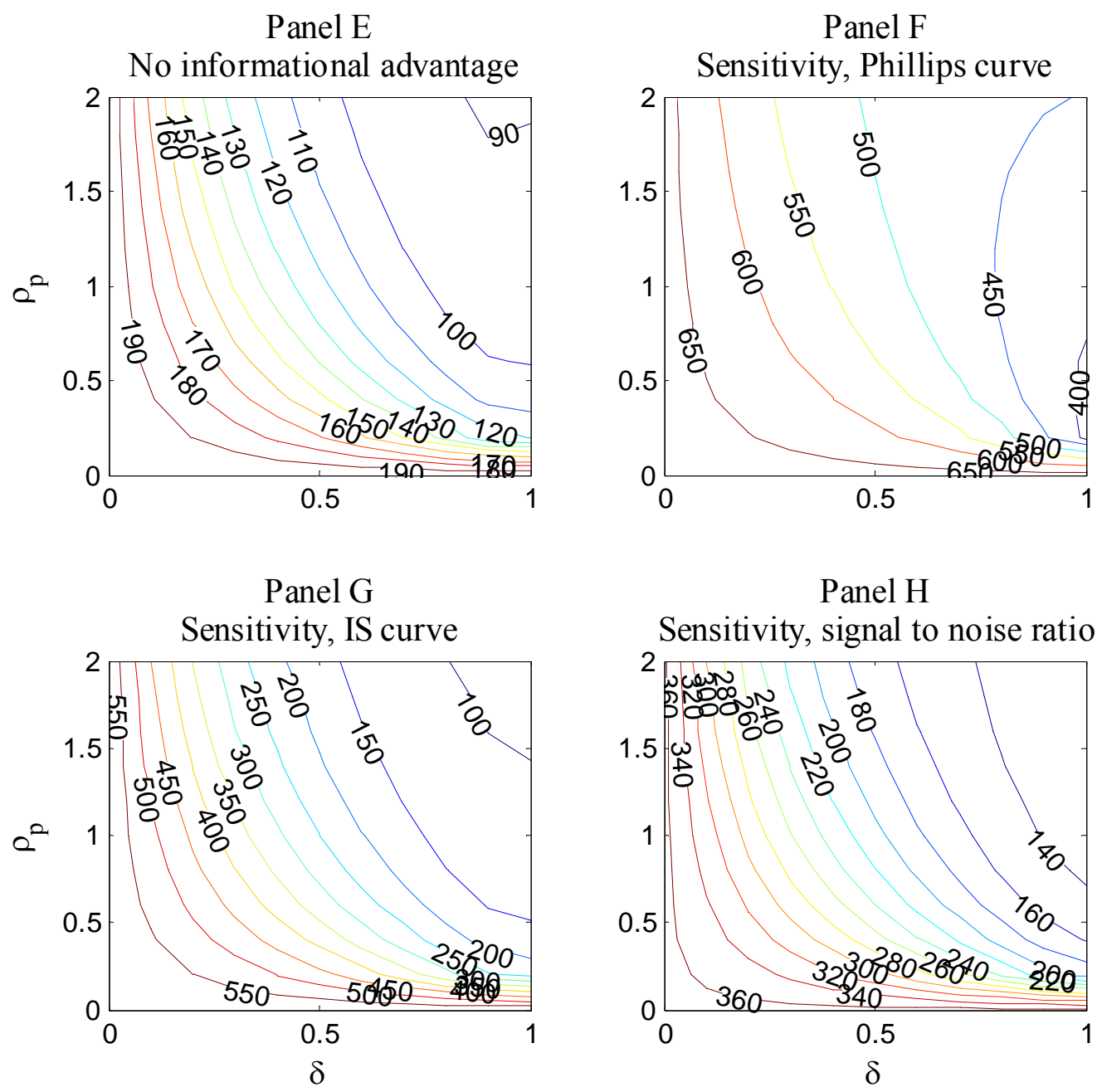

\section{Panel $\mathrm{H}$}

Sensitivity, signal to noise ratio

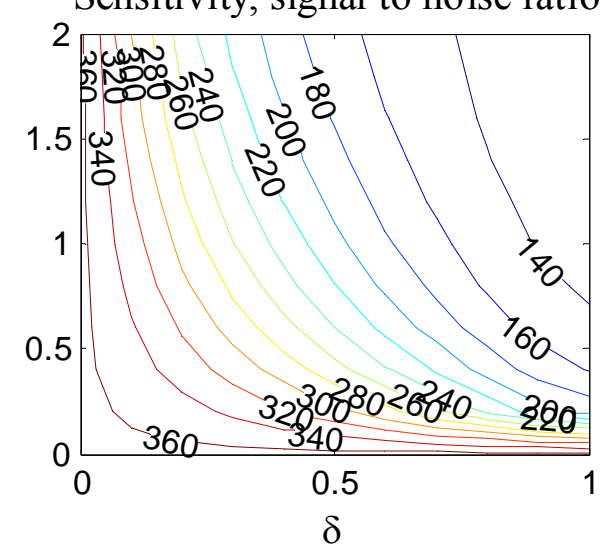

Note: See appendix Table A2 for the calibration details. 